\title{
Programming isotype specific plasma cell differentiation
}

Brett W. Higgins, Andrew G. Shuparski, Karen B. Miller, Amanda M. Robinson, Louise J. McHeyzer-Williams \& Michael G. McHeyzer-Williams*

Department of Immunology and Microbial Sciences,

The Scripps Research Institute, La Jolla, California 92037, USA

*Correspondence: mcheyzer@scripps.edu 


\begin{abstract}
Antibodies are produced across multiple isotypes with distinct properties that coordinate initial antigen clearance and confer long-term antigen-specific immune protection. Here, we interrogate the molecular programs of isotype-specific murine plasma cells (PC) following helper $\mathrm{T}$ cell dependent immunization and within established steady-state immunity. Using integrated single cell strategies, we reveal conserved and divergent components of the rapid effector phase of antigen-specific $\operatorname{lgM}^{+}$versus inflammation modulating programs dictated by $\operatorname{lgG} 2 \mathrm{a} / \mathrm{b}^{+} \mathrm{PC}$ differentiation. During antibody affinity maturation, the germinal center (GC) cycle imparts separable programs for post-GC inhibitory $\lg G 1^{+}$and inflammatory $\lg G 2 a / b^{+} P C$ to direct longterm cellular function. In the steady-state, two subsets of $\operatorname{lgM}^{+}$and separate $\operatorname{lgG} 2 \mathrm{~b}^{+} \mathrm{PC}$ programs clearly segregate from splenic $\lg \mathrm{A}^{+} \mathrm{PC}$ programs that emphasize mucosal barrier protection. These diverse isotype-specific molecular pathways of PC differentiation control complementary modules of antigen clearance and immune protection that could be selectively targeted for immunotherapeutic applications and vaccine design.
\end{abstract}

Keywords: Plasma Cell, Isotype, Class Switch Recombination, Germinal Center, T helper cell, single cell RNA-seq, B Cell, Antibody 


\section{INTRODUCTION}

In response to $\mathrm{T}$ dependent (TD) antigen, antigen-presenting $\mathrm{B}$ cells are activated by follicular helper $\mathrm{T}$ cells $\left(\mathrm{T}_{\mathrm{FH}}\right)(1,2)$, and undergo class switch recombination (CSR) through cytokine driven signaling cascade events(3-5). As CD4 ${ }^{+} \mathrm{T}$ helper cells and innate lymphoid cells (ILCs) are categorized into subsets based on discrete immune function(6, 7), B cells can be similarly assorted by antibody class $(8,9)$. $\operatorname{lgM}^{+}$antibody is secreted as a pentamer for aviditybased antigen neutralization, complement activation or labeling for phagocyte uptake. Each secreted antibody elicits separable immune responses through class specific $F_{c}$ receptor binding such as type 1 inflammation induction by $\lg G 2 a / b^{+}$subclasses and type 2 inflammation reduction by $\lg 1^{+}$antibody(10-12). $\lg \mathrm{A}^{+}$antibody can be uniquely produced as a dimer wrapped by a secretory component for translocation across epithelial layers to provide type 3 mucosal barrier defense and enable commensal microbiota tolerance(13-15). The role of PCs extends beyond antibody secretion as $\lg \mathrm{M}^{+}$and $\lg \mathrm{A}^{+} \mathrm{PC}$ s have been linked with interleukin (IL)-10, IL-17, IL-35, and tumor necrosis factor (TNF)- $\alpha$ secretory activity(16-20). Thus, PC immune effector activity is divided by antibody isotype; however, there remains little resolution of the divergent transcriptional control of immune module function across these class-specific PC compartments.

PC terminal differentiation requires expression of a conserved transcriptional program, guided by the upregulation of master transcriptional regulators Blimp-1, Xbp1 and IRF4 with concurrent downregulation of B cell lineage driving factors such as Bcl6, Pax5, Pu.1 and IRF8(2129). During antigen clearance, an initial wave of PC differentiation produces an effector cohort that survives only days secreting low affinity antibody for antigen control and Fc receptor driven immune regulation. This early immune response module is influenced by $T_{F H}$ cell driven CSR which produces varied PC antibody classes. Subsequently, B cells enter a geminal center (GC) reaction under the cognate direction of $\mathrm{T}_{\mathrm{FH}}$ cells to undergo affinity maturation and exit as postGC 'memory' PCs capable of long-term survival for durative antigen-specific protection(30-34). 
During this 'memory' phase of the immune response, $\mathrm{T}_{\mathrm{FH}}$ cell directed GC cycling likely imprints supplementary molecular programming necessary for post-GC PC function and survival. It remains unclear the extent to which CSR and GC cycling impact the expression of ancillary molecular programs that divide these PC cohorts functionally at the single cell level.

Targeted immunization with model antigen and the unimmunized "steady-state" murine models provide access to varied classes of PC. TD antigen NP-KLH (4-hydroxy-3nitrophenylacetyl conjugated to Keyhole Limpet Hemocyanin) synchronizes intact immune systems in vivo allowing access to pre-GC and follicular B cells for single cell molecular analysis $(35,36)$. Using NP-KLH and TLR4 agonist MPL as an adjuvant, we have detailed an antigenspecific $\lg \mathrm{G} 2 \mathrm{a} / \mathrm{b}^{+}$and $\lg \mathrm{G} 1^{+}$dominated response with the effector pre-GC phase consisting of an unmutated PC compartment at day five, and a post-GC phase by day fourteen where all PCs exhibit somatic mutation(8, 36-38). In contrast, an unimmunized "steady-state" murine system continually exposed to environmental and gut microbiota antigen presents an ongoing, polyclonal immune response composed of $\operatorname{lgM}^{+}, \lg \mathrm{A}^{+}$, and $\operatorname{lgG}^{+} \mathrm{B}$ cell classes. As a result, the steady-state system provides the capacity to compare isotype-specific PC subsets distributed across multiple lymphoid organs $(13,39)$. Combining the use of these two models enables the interrogation of discrete molecular programming expressed by each class and subclass of PC.

Here we utilize a quantitative gene targeted RNA sequencing strategy $(40,41)$ to interrogate the underlying transcriptional heterogeneity of class specific PCs at the single cell level. We demonstrate that antigen-specific effector $\operatorname{lgM}^{+}$and inflammatory $\operatorname{lgG}^{+} \mathrm{PC}$ subclasses segregate transcriptionally with divergent molecular programs acquired during the GC reaction. This divergence was recapitulated in the steady state by $\operatorname{lgM}^{+}, \lg G 2 b^{+}$and $\lg \mathrm{A}^{+} \mathrm{PC}$ shich exhibited unique and defining molecular programs that extended further into two phenotypically and transcriptionally distinct subpopulations within the $\operatorname{lgM}^{+}$compartment. These studies indicate 
divergent transcriptional programs are imprinted according to broad immune response modules in both effector and post-GC pathways of PC differentiation. We propose that differential isotypespecific plasma cell programming can be selectively targeted for immune therapeutic modification and future vaccine design.

\section{RESULTS}

\section{Antigen-driven segregation of isotype-specific PC differentiation}

Acute response PC compartments express antigen-binding BCR following helper $\mathrm{T}$ cell dependent immunization at both the extrafollicular effector PC phase (Day 5) and the post-GC PC differentiation phase(9, 23, 38) (Day14; Fig 1A-B; Supplemental Fig 1A-F). These flow cytometry-based isolation strategies capture the majority of PC activity in vivo as seen by antigenbinding and isotype-specific ELISPOT (Fig 1C; Supp Fig 1G-H). Expression of both CD138 and intracellular Blimp-1 protein attest further to the identity of antigen-specific $\operatorname{lgM}^{+}$and classswitched PC at the effector and post-GC 'memory' PC phase in the draining lymph nodes (LN) and bone marrow (BM) (Fig 1D; Supp Fig 1D-E). Cell cycle indicator Ki67 varied across antigenspecific PC compartments with highest levels at day 5 in both $\operatorname{lgM}^{+}$and class-switched compartments (Fig 1D). Bimodal distributions of Ki67 at day 14 post-GC represents time since GC exit and terminal differentiation both locally and within the BM. As expected, expression of the B cell isoform of CD45, B220, and the BCR co-receptor CD19 decreased differentially by location and time but additionally by class, highlighting the potential for programmatic divergence in vivo (Fig 1D).

$\operatorname{lgM}^{+}$PCs represented only a minor fraction of responders to this TD antigen and MPL adjuvant. In contrast, among the IgG subclasses, type 1 inflammatory $\lg \mathrm{G} \mathrm{a}^{+}$and $\operatorname{lgG} 2 \mathrm{~b}^{+}$ emerged rapidly to dominate by day 5 , accompanied by $\operatorname{lgG} 1^{+}$at day 7 with equivalent numbers of this type 2 anti-inflammatory isotype present post-GC by day 14 (Fig 1E-F; Supp Fig 1F). This 
antigen-specific PC differentiation model provides experimental access to early effector PCs expressing $\operatorname{lgM}^{+}$and temporally and developmentally separate $\operatorname{lgG}^{+}$subclasses to interrogate for transcriptional divergence at the single cell level.

\section{Divergent IgM and IgG effector PC Programs}

As immunoglobulin mRNA makes up over $70 \%$ of sequenced cDNA species using global sequencing approaches in $\mathrm{PCs}(29,42,43)$, we developed a more targeted single cell RNA-seq protocol for these studies $(40,41)$. This quantitative and targeted RNA sequencing strategy (single cell qtSEQ) begins with high dimensional FACS sorted and indexed antigen-specific PC that are tracked and processed as single cells (Fig 2A). We currently target $\sim 500$ gene products designed to exclude immunoglobulin genes but focus on expressed mRNA for transcriptional modifiers translocating to or residing in the nucleus $(n=152)$, cell surface molecules $(n=203)$ and cytoplasmic and secreted species ( $n=91$ and $n=51$, respectively). Across this target set, barcoding was designed to identify reads from each individual sorted cell with the capacity to quantify per cell expression using unique molecular identifiers (UMIs) in a similar manner to global approaches (Supplementary Fig 2A). Dimensionality reduction of cell surface phenotype and gene expression distinguished the index sorted effector $\operatorname{lgM}^{+}$and $\operatorname{lgG}^{+}$PC compartments (Fig 2B-C). Relying on statistically significant divergence in gene expression, expression fold change (Fig 2D-F) and averaged heatmap representations of scaled signals in heatmaps (Fig 2G), we establish multiple isotype-segregating components of the $\operatorname{lgM}^{+}$and class-switched antigenspecific effector PC transcriptional program.

The loss of central naive B cell transcriptional programs (Bc/6, Pax5, Bach2, Spib) were a cardinal feature of early effector IgM $^{+}$PC differentiation (Fig 2D; Supplementary Fig 2B). These substantial changes in transcriptional regulation were accompanied by increased PC lineage drivers (e.g., Prdm1, Irf4, Xbp1, Pou2af1) with some factors expressed significantly higher in 
extrafollicular $\operatorname{lgM}^{+}$effector PC compared to their class-switched counterpart (Fig 2D,E; Supplementary Fig 2C). Multiple other transcriptional modifiers were differentially expressed at higher (Skil, Ncor2, Pou2f2, Plac8, Nfatc2) or lower levels (Smad4, Traf3, Pparg, Bhlha15 and Bhlhe41) allow separation of the central programs of $\operatorname{lgM}^{+}$from $\operatorname{lgG}^{+}$class-switched $\mathrm{PC}$ at the effector stage (Fig $\mathbf{2} \mathbf{F}, \mathbf{G})$. IgM $^{+}$PCs may express ancillary effector functions related to differentially expressed secretory molecules (e.g., Tgfb2, Ltbp3, I/1a) in contrast to $\operatorname{lgG}^{+} \mathrm{PC}_{\text {from }}$ this stage (e.g., I/15, S/pi, S100a9; Fig 2F,G). Finally, there are significant differences in expression of surface effector molecules including chemokine receptors and cell adhesion mediators between PC subsets (e.g., Ccr1, Tnfrsf13b, Slamf7 Ctla4, Cd79a in IgM+; Timd2, II9r, Cxcr3, Sele in IgG; Fig 2G). This programmatic heterogeneity can markedly impact class specific BCR responsiveness, immunomodulation, migratory behavior, and survival requirements. Together, $\operatorname{lgM}^{+}$and $\operatorname{lgG}^{+}$effector $\mathrm{PC}$ compartments demonstrate divergent transcriptional programs with evidence for separable secretory and surface modifiers that direct class-specific immune function.

\section{Inflammatory subclass IgG effector PC programs.}

Closer scrutiny of $\operatorname{lgG} 2 \mathrm{a}^{+}$and $\operatorname{lgG} 2 \mathrm{~b}^{+}$effector PC (Fig 3A; Supplementary Fig 3) revealed further significant transcriptional differences between the cells expressing these early inflammatory mediating antibody subclasses (Fig 3B-D). Expression of major transcriptional regulators are significantly higher in IgG2a ${ }^{+} \mathrm{PC}$ (Foxj1, KIf6, KIf7, Bcl6b and IIf1) in contrast to IgG2b+ PCs (Pparg, Bhlha15, Bhlhe41, Xbp1, Ikzf1; Fig 3D,E). Differential upregulation of secretory molecules that have been linked with eliciting inflammatory responses (II22, S100a9, Gzma in IgG2a+; II15 in IgG2 $\mathrm{b}^{+}$) as well as surface expressed proteins (Tnfrsf1b,Tnfsf9, Tnfsf14, Itgb2 in IgG2a+; Havcr2 in IgG2 $b^{+}$) further distinguished a separable lgG2a+ transcriptional module from IgG2 $b^{+}$PCs. Consistent with the inflammatory functions of $\operatorname{lgG} 2 a / b$ subclass Cxcr3 is expressed highly compared to IgM and validated with protein expression. Surface expression of 
MHC-II by effector PCs suggested conserved retention of antigen presentation capacity, though differential Cxcr3 and B220 expression emphasized shared programmatic components of $\operatorname{lgG}^{+}$ subclasses that still differed from $\operatorname{lgM}^{+}$PCs (Fig 3F-H). The separation of antigen-specific effector PCs into $\operatorname{lgG} 2 a^{+}$and $\operatorname{lgG} 2 b^{+}$subclasses emphasizes the existence of dichotomous subclasslinked molecular programming with evidence for heterogenous inflammatory response control.

\section{Divergent isotype-specific post-GC PC programs.}

The GC cycle is fully operative by day 14 of this immune response producing antigenspecific memory B cells and post-GC PCs that express affinity-matured $\mathrm{BCR}(8,35-38,44-47)$. This established GC reaction produces equivalent numbers of anti-inflammatory $\operatorname{lgG} 1^{+}$post-GC $\mathrm{PC}$ and their inflammatory $\lg \mathrm{G}_{2} \mathrm{a}^{+}$and $\lg \mathrm{g}_{2} \mathrm{~b}^{+}$post-GC PC counterparts (Fig1E; Fig 4A-B). Compared to naïve B cells, post-GC $\operatorname{lgG} 1^{+} \mathrm{PCs}$ upregulated master transcriptional regulators involved in cell cycling, antibody secretion and UPR control (e.g., Ube2c, Mki67, E2f2, Ell2, Xbp1, Atf4, Bhlha15), cytokine linked secretory components (e.g., Ifng, II15, I/22) and surface molecules (e.g., Cd44, Itgal, Cd93, Cd28, Cd80, Cd276, Cd9) that direct long-term cellular function (Fig 4CE).

Comparison between post-GC PCs indicated IgG1+ post-GC PCs expressed significantly higher levels of central transcriptional regulators (Spib, Bach2, Pou2af1, Creb3/2, Irf4, Ell2) that would coordinate separable programs upon GC exit. In contrast, lgG2a ${ }^{+}$post-GC PCs differentially expressed a separate set of regulators (IIf1, Kmt2d, Relb, Nfatc2) that segregate further against IgG2b $b^{+}$post-GC PC (Hif1a, KIf4, Klf6, Bhlha15, Plac8, Batf, Notch1, Prdm1 and Atf4) (Fig 4F-H). Surface expressed, cytosolic and secreted components of these programs begin to indicate the impact of the transcriptional differences on subclass specific post-GC PC function. $\lg \mathrm{G} 1^{+}$post-GC PC differentially expressed multiple molecules with capacity to elicit divergent function (Plxnd1, TIr3, Cd24a, Blk, Lamp1; Fig 4F,I); while IgG2a ${ }^{+}$post-GC PCs exhibited unique 
gene upregulation including a set of secretory molecules (Isg15, Ltbp3, I/1a) associated with directing a range of inter-cellular functions (Fig $4 \mathbf{I}, \mathbf{G})$. In the context of the targeted gene set, $\operatorname{lgG} 2 \mathrm{~b}^{+}$post-GC B cells differentially expressed multiple segregated programs, notably a series of cellular adhesion molecules (Cd9, Cd81, Cd80, Ptprc, Tigit, Slamf9; Fig 4H,I). These divergent transcriptional changes remain prominent and persistent even following the complex behavior of somatic hypermutation and antigen-driven selection that is paramount in the GC reaction.

As described above, we used Ki67 as a marker of recent cell cycling and hence as a proxy for recent GC cycle exit in post-GC PCs. We utilized index tracing to divide post-GC PCs by Mki67 expression and determined that each IgG subclass contained equal frequencies of $M k i 67^{+}$cells (Supplementary Fig 4B). As expected of cells more recently cycling, Mki67 $7^{+} \mathrm{PCs}$ were more transcriptionally active with enrichment of programs associated with apoptosis, cell division and replication compared to the Mki67- population (Supplementary Fig 4C,D).

\section{Separable inflammatory post-GC PC programs.}

While post-GC PCs retained expression of MHC-II similar to effector PCs, they exhibit differential expression of CXCR3 and FAS (Fig 5A). Furthermore, gene program driven dimensionality reduction separates effector and post-GC PCs (Fig 5B). Through comparison of inflammatory class effector PCs to post-GC PCs, we can establish unique molecular programs imprinted by GC cycling (Fig 5C-D). Dividing our analysis into $\lg \mathrm{G}_{2} \mathrm{a}^{+}$and $\lg \mathrm{G}_{2} \mathrm{~b}^{+}$subclasses resolved subclass specific transcriptional programs that emerge post-GC (Fig 5E-G). The reliance on highly influential modules of transcriptional regulation at day 5 (Myc, Foxj1, Pcna, Notch2 in IgG2a; E2f2, Ciita, Bhlha15, Pparg, Akt1, Smad4, Irf4, Ube2c in IgG2b ${ }^{+}$) was significantly shifted by day 14 in the post-GC PC compartment, which upregulated a separate series of nuclear factors (Relb, Kmt2d in IgG2a ${ }^{+}$; KIf7, Skil in both; Stat6, Mef2c in IgG2b ${ }^{+}$) (Fig 5G). 
Beyond transcriptional regulation there were significant changes in expression of important cell membrane expressed regulators of immune function which extended further to segregation by antibody subclass; we revealed changes from day 5 effector PCs (e.g., Tnfrsf1b, Tnfsf18, I/1r2, in IgG2a; Cxcr3, Cd244, Ly6D and Cd24a in IgG2b) to post-GC PCs (e.g., Cd40I, Cd22, Tnfsf11 in IgG2a; I/1rn, Cd80, Slamf9, Cd86, Cd93 in IgG2b). Post-GC PCs also upregulated secretory factors (Ltbp3, II1a, SIpi, Ccl8, Ifng, II21) not represented in effector PC compartments. These subclass specific components of post-GC changes, including chemokine receptors, B7 family receptors, and adhesion molecules suggest shifts in cellular function imprinted by the GC program prior to post-GC PC differentiation.

\section{Divergent IgM and IgG2b PC programs in the steady state.}

Next, we chose to broaden our molecular analyses to the range of isotype-specific PC found in the steady-state spleen. While CD138 is a reliable PC marker in the context of antigenbinding responses, Blimp-1 reporter expression was used in these steady-state studies. High levels of Blimp-YFP in lgM+ or class-switched B cells served to identify antibody-secreting PC of separable isotype (Fig 6A; Supplementary Fig 5A-B). The $\operatorname{lgM}^{+}$and $\operatorname{lgG} 2 \mathrm{~b}^{+}$subsets broadly separated in UMAP clusters based on the full range of gene expression from qtSEQ analysis (Fig 6B).

In contrast to $\mathrm{MHCll}-$ expressing TD antigen-specific $\operatorname{lgG}^{+}$and $\operatorname{lgM}^{+} \mathrm{PC}$ (Fig 3F), steadystate $\operatorname{lgM}^{+} \mathrm{PCs}$ presented across two phenotypically distinct compartments with the majority expressing high surface levels of BTLA (B and T lymphocyte attenuator) with low to negligible MHC-II (Fig 6C; Supplementary Fig 5C). The BTLA ${ }^{\text {hi }}$ IgM subset upregulated a divergent set of transcriptional regulators (e.g., Irf1, Irf4, Runx3, Crlf2, Bcl2, Fosb, Atf6, Egr2, Smad3, Nfatc2) that contrasted significantly to the MHC-II ${ }^{\text {hi BTLA }}{ }^{\text {lo }}$ subset (e.g., Ikzf2, Runx2, Notch 1, Notch2, Bhlha15, Mki67, Pcna, Top2a, Ube2c, Eaf2) (Fig 6D-E). These transcriptional differences 
extended to cell surface molecules (e.g., Ly6d, Slamf9, Slc3a2, Tmem176b, Ifnar2 in BTLA ${ }^{\text {hi; }}$ Ly6c1, Ly75, Tnfsf9, Cd9 in BTLA ${ }^{\mathrm{lo}}$ ) as well as intracellular and secreted cellular components (Itch, Ifnb1, Ifng in BTLA ${ }^{\text {hi; }}$ Mzb1, Edem1, Aurkb, II22 and II1a in BTLA ${ }^{\text {lo }}$ ). These differences demonstrate separable control over a wide spectrum of potential $\operatorname{lgM}^{+} \mathrm{PC}$ effector functions for these two subsets with further transcriptional divergence from recently formed antigen-specific effector $\operatorname{lgM}^{+}$(Supplementary Fig 5D).

$\lg G 2 b^{+} P C$ from the steady state shared many transcriptional features seen in the NPspecific $\lg \mathrm{G}_{2} \mathrm{~b}^{+}$response (Supplementary Fig 5E). However, significant $\operatorname{lgG} 2 \mathrm{~b}^{+} \mathrm{PC}$ transcriptional differences were seen across all classes of cell function regulators (nuclear, cell membrane, intracellular and secretory) when contrasted to naive B cells and the broad steadystate $\operatorname{lgM}^{+}$PC programs (Fig 6 F-I).

\section{Distinct IgA PC programming for mucosal immunity.}

As expected, due to their origins and mucosal targeting function, IgA-expressing PC are most abundant in the Peyer's patch but can also be found in the BM and the SP at steady-state (Supplementary Fig 6). All Blimp $-1^{+} \lg \mathrm{A}$ PC expressed high levels of both intracellular and surface IgA (Supplementary Fig 7A). Using the Blimp1-reporter model, we isolated IgM ${ }^{\text {neg }}$ classswitched $\lg \mathrm{A}^{+}$PC for gene expression studies (Fig 7A) which broadly separated in UMAP clusters based on the full range of gene expression from qtSEQ analysis (Fig 7B). In contrast to $\operatorname{lgM}^{+} \mathrm{PCs}$, the majority of the $\lg \mathrm{A}^{+} \mathrm{PC}$ cohort expressed intermediate to high levels of $\mathrm{MHC}-\mathrm{Il}$ and lower levels of BTLA (Supplementary Fig 5C; Fig 7C). However, IgA $\mathrm{A}^{+} \mathrm{PC}$ maintain high levels of the BCR co-receptor CD79b, akin to $\lg ^{+} \mathrm{PC}$ and opposite to $\lg \mathrm{G} \mathrm{b}^{+} \mathrm{PC}$. (Fig 7D). $\lg \mathrm{A}^{+}$expression of CD98 and PD-L1 was similar to $\operatorname{lgM}^{+}$PCs but had the lowest expression of the BCR co-receptor CD19. Only $\lg \mathrm{A}^{+} \mathrm{PCs}$ expressed a substantial fraction of Ccr9, contrasted by Cxcr3 expression by $\operatorname{lgM}^{+}$and $\operatorname{lgG}^{+}$PCs (Fig 7D; Supplementary Fig 7B-D). As all of these protein expression 
trends extended into the BM derived population of $\lg \mathrm{A}^{+} \mathrm{PCs}$, this indicated class conserved rather than location driven programming (Supplementary Fig 7E). Hence, even at the broad level of surface phenotype, it is clear that $\lg \mathrm{A}^{+} \mathrm{PC}$ express a different molecular program to $\mathrm{PC}$ of other antibody isotypes.

Comparing the $\lg \mathrm{A}^{+}$transcriptional program to naive $\mathrm{B}$ cells highlighted many of the canonical features of the PC program seen across all PC isotypes (decreased B cell identity: Pax5, Bach2, Spib, Bcl6; decreased antigen processing and presentation: CD74, H2-dma, H2ab1; increased lineage transcription factors: Prdm1, Irf4, Pou2af1; increased Sdc1, Ly6c1, CD44, Mzb1, Rexo2) (Fig 7E; Supplementary Fig 7F). However, multiple molecular features were exaggerated in the steady-state $\lg \mathrm{A}^{+} \mathrm{PC}$ compartment in contrast to $\lg \mathrm{M}^{+}$and $\lg \mathrm{G}_{2} \mathrm{~b}^{+}$such as the increased expression of major transcriptional regulators (Runx2, Klf13, Gata1, Jund), TGF- $\beta$ responsive transcription factors (KIf4, Cited2), UPR and secretion modifiers (Atf4, Xbp1, Ell2, Irf2)

(Fig 7 F-G). That IgA ${ }^{+}$PCs exhibited differential expression of chemokine receptors (Ccr7, Ccr9, Ccr10), the highest levels of growth factor receptors (Tnfrsf13b, Tnfrsf17), surface receptor sensors (Tmem176b, Lgals, TIr5) and secretory environmental modifiers (Ifng, S100a9) indicating the capacity for enhanced chemotaxis, survival, and environmental sensing in the mucosal microenvironment over $\operatorname{lgM}^{+}$and $\operatorname{lgG} 2 \mathrm{~b}^{+}$PCs. Expression of these divergent phenotypic and transcriptional programs may uniquely and differentially impact $\lg \mathrm{A}^{+} \mathrm{PC}$ localization, survival, and effector functionality.

\section{DISCUSSION}

In these studies, a targeted single cell RNA sequencing platform connected surface phenotype with unique transcriptional programming of class specific PCs. Divergent transcriptional programming defined early forming $\operatorname{lgM}^{+}$from $\operatorname{lgG}^{+}$subclass $\mathrm{PC}$ which indicated different effector roles. By comparing effector and post-GC PC cohorts, we highlighted the 
acquisition of unique molecular programs resulting from $\mathrm{T}_{\mathrm{FH}}$ cell directed $\mathrm{CSR}$ and $\mathrm{GC}$ cycling necessary for memory phase survival and function. Extension into steady state immunity supported the broad $\operatorname{lgM}^{+}$and $\operatorname{lgG}^{+} \mathrm{PC}$ transcriptional divergence seen in effector PCs yet revealed two transcriptionally distinct subpopulations within $\operatorname{lgM}^{+} \mathrm{PCs}$. Interrogation of $\lg \mathrm{A}^{+} \mathrm{PCs}$ revealed programmatic capacity for mucosal protective functions. Taken together, these separable immune response modules for PC transcriptional control emphasize unique class specific molecular programming that shape early effector responses and impact long-live 'memory' PC compartments.

Effector PCs are formed rapidly upon antigen exposure and are important for differentially impacting immune responses through class specific antibody binding of Fc receptors(10-12). Effector IgM+ PCs upregulated genes coding for Ltbp3 and Tgfb2 that form a secreted complex which can induce $T_{H} 17$ or regulatory $T$ cell $\left(T_{R E G}\right)$ formation in a concentration dependent manner(48), suggesting effector $\operatorname{lgM}^{+}$PCs may be capable of influencing a pro or antiinflammatory environment. Additionally, $\operatorname{lgM}^{+}$upregulation of secreted costimulatory cytokine IL1a may impact proinflammatory II-1R driven signaling. In line with their antibody driven inflammatory function, $\lg \mathrm{G}_{2} \mathrm{a}^{+}$and $\operatorname{lgG} 2 \mathrm{~b}^{+} \mathrm{PCs}$ each upregulated additional proinflammatory molecules; however, both subclasses also upregulated anti-inflammatory S/pi known to prevent runaway proinflammatory activity(49). Therefore, we demonstrate effector PCs are transcriptionally poised for separable class linked functionality via additional secreted molecules.

Gene upregulation of inhibitory cell surface proteins (Ctla4, Slamf7) by $\operatorname{lgM}^{+} \mathrm{PCs}$ would permit $\mathrm{T}$ cell modulation during $\mathrm{T}$ cell cognate contact, while $\operatorname{lgG} 2 \mathrm{a}^{+} \mathrm{PC}$ elevated expression of Tnfsf9 (CD137L), involved in bidirectional signaling after cognate contact, may direct increased inflammatory activity(50). As all effector PCs retained MHC-Il expression, they may participate in $T$ cell cognate interactions and induce additional $T_{H}$ cell functions through $M H C-I I$ antigen 
presentation as we have previously demonstrated in class switched post-GC PCs(38). Thus, each class of effector PC may be capable of impacting ongoing immune responses through differentially impacting and influencing $\mathrm{T}_{\mathrm{FH}}$ cell functionality.

The GC reaction is critical for generating antigen specific immunological memory through the formation of memory B cells and post-GC PCs poised for long term functionality in specialized survival niches. During GC cycling, higher affinity B cells receive increased $T$ cell help $(51,52)$ and are more likely to exit as $\mathrm{PCs}(31-33,53-55)$. Additional T cell interactions may be responsible for imprinting unique transcriptional programs in post-GC PCs. After transit to the BM, PCs exhibit transcriptional and phenotypic changes(29, 56-58). However, upon GC exit it is already apparent that post-GC PCs are broadly and indelibly changed to accommodate their 'memory' role. For example, they lose cell cycle and division programs that allow entry into a quiescent state and negative regulators of apoptosis for long term survival. Post-GC PCs upregulated of extrinsic signal receptors, costimulatory molecules, and cell adhesion regulators. The effector molecules could contribute to enhanced T cell interaction during GC cycling and may be important for survival niche maintenance via exogenous secreted survival signals and extrinsic contact from support cells such as $\mathrm{T}_{\mathrm{REGs}}(59)$.

The steady state $\operatorname{lgM}^{+}$PC compartment phenotypically split into two subsets defined by BTLA $^{\text {hi MHC-II }}{ }^{\text {lo }}$ and BTLA ${ }^{\text {lo MHC-II }}{ }^{\text {hi }}$ expression. As mentioned earlier, subsets of $\mathrm{CD}_{138^{+}} \operatorname{lgM}^{+}$ PCs have been shown to secrete IL-10 and IL-35 which suppress effector CD4 ${ }^{+}$cells and innate cells to enact a regulatory $B$ cell $\left(B_{R E G}\right) \operatorname{role}(19,60,61)$. The $B T L A^{\text {hi } M H C-I I ~}{ }^{\text {lo }} \operatorname{lgM}^{+}$compartment identified here exhibited shared programs with regulatory $\lg ^{+} \mathrm{PCs}$, such as higher expression of Irf4(19), downregulation of cell cycle linked genes, reduced MHC-II protein and expression of BLTA (associated with Btla gene upregulation in regulatory $\left.\operatorname{lgM}^{+} \mathrm{PCs}\right)(60)$. In contrast, the high protein expression of $\mathrm{MHC}-\mathrm{Il}$ by the second $\mathrm{IgM}^{+}$subpopulation was more similar to helper $\mathrm{T}$ cell 
driven antigen-specific PCs and steady state $\operatorname{IgG}^{+} \mathrm{PCs}$. This $\mathrm{BTLA}^{\mathrm{lo} M H C-\mathrm{II}^{\mathrm{hi}}} \operatorname{IgM}^{+}$compartment upregulated antigen processing and presentation programs, T cell costimulatory proteins (e.g., Cd40lg, Tnsf9) and signal molecules, which may indicate capacity for modulating $T_{H}$ cell function during MHC-II antigen presentation as described previously(38). Thus, we propose that the phenotypically defined subsets represent transcriptionally distinct $\operatorname{lgM}^{+} \mathrm{PC}$ cohorts: a $\mathrm{B}$ regulatory compartment and a T cell interacting compartment primed for antigen presentation that is TD in origin.

In the steady state, $\mathrm{T}$ cell dependent gut derived antigens generate $\lg \mathrm{A}^{+} \mathrm{B}$ cells that can enter GCs to undergo affinity maturation and exit as post-GC PCs(39, 62-65). Expression of PDL1 by $\lg \mathrm{A}^{+} \mathrm{PC}$ s may be retained from GC cycling where PD-1/PD-L1 interactions are critical for cell survival and post-GC PC formation(66). Additionally, PD-L1 $1^{+} \mathrm{MHCl}{ }^{+} \operatorname{IgA}{ }^{+} \mathrm{PCs}$ in the lamina propria induced FoxP3 ${ }^{+} \mathrm{T}_{\mathrm{REG}}$ formation in the presence of TGF- $\beta(67)$ which are important for maintaining $T_{H} 17$ and $\lg A^{+} P C$ homeostasis(68). We detected $\lg A^{+} P C$ upregulation of many complementary molecular programs with $\mathrm{T}_{\mathrm{H}} 17$ cells, such as transcription factors (KIf4, Cited2), and surface protein expression (e.g. Tmem176b(69), Fas(70), and chemokine receptors Ccr7, Ccr9, Ccr10(71)) that may confer similar mucosal defense functionality. Though $\mathrm{T}_{\mathrm{H}} 17$ cells can induce formation of $\lg \mathrm{A}^{+} \mathrm{PCs}(72)$, upregulation of Ifng by $\lg \mathrm{A}^{+} \mathrm{PC}$ may in turn allow modulation of $\mathrm{T}_{\mathrm{H}} 17$ formation and function through secretion of IFN- $\mathrm{Y}(73)$. These reciprocal molecular programs of $T_{H} 17$ and $\lg A^{+}$PCs may result from shared formation in a TGF- $\beta$ rich environment prior to $\lg \mathrm{A}^{+} \mathrm{PC}$ survival niche localization in the spleen $(74,75)$, similar to previous reports that gut $\lg \mathrm{A}^{+} \mathrm{PC}$ translocate to bone marrow survival niches for systemic antibody secretion(76-78).

Previous studies on humans have identified preferential and sequential switching capacity of B cells(79) and identified class linked heterogeneity which may influence B cell fate and function(80-82). As each murine antibody class investigated in this study has a homologous 
isotype in humans, this work is applicable to ongoing human research, particularly for PC driven diseases, immunotherapeutics and vaccine design. Programmatic studies in Multiple Myeloma have led to approval of the anti-Slamf7 drug Elotuzumab(83) and proposals for Hif1a suppression as therapy(84); our studies identified upregulation of Slamf7 in $\lg ^{+} \mathrm{PCs}$ and Hif1a in $\operatorname{lgG} 2 \mathrm{~b}^{+}$ PCs. Therefore, further exploration of the class specific molecular programs in PCs can potentially identify targetable surface molecules or transcriptional pathways pertinent to PC directed diseases.

Chimeric antigen receptor (CAR) T cells marked the advent of synthetically engineered immunotherapeutics, which has now expanded into B cells(85-87). The specificities of known neutralizing antibodies introduced to BCR gene loci generated target-specific antibodies without prior antigen encounter, GC cycling or affinity maturation after PC induction(85-87). Beyond specificity, these 'synthetic' PCs need to function and survive long term in appropriate niches. Our studies detailing the molecular programming of post-GC 'memory phase' PCs provides elements of an isotype-specific transcriptional roadmap for future studies. Previous work has indicated B cell class may impact GC entry(81), or terminal differentiation pathway into memory B or PC(88). Here our study emphasizes that B cell class may impact immune function beyond Fc binding. We propose that each class of PC is transcriptionally primed to differentially participate in and impact ongoing immune responses via ancillary effector functionality that must be considered during vaccine design. 


\section{MATERIALS and METHODS}

\section{Mice}

C57BL/6 (B6), B6.CD45.1 (B6.SJL-Ptprc ${ }^{\mathrm{a} P e p c}$ /BoyJ) and Blimp1-YFP mice (provided by Susan Kaech, Salk Institute) were bred and housed in specific pathogen-free conditions. All experiments were done in compliance with federal laws and institutional guidelines as approved by The Scripps Research Institutional Animal Care and Use Committee.

\section{NP-KLH Immunization}

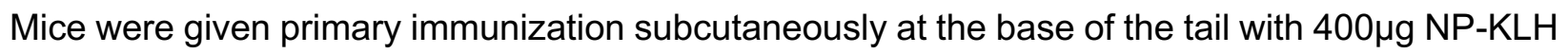
(4-hydroxy-3-nitrophenylacetyl (Biosearch) conjugated to keyhole limpet hemocyanin (Pierce)) mixed with adjuvant based on Monophosphoryl Lipid A.

\section{Flow Cytometry}

Single cell suspensions of draining (inguinal and periaortic) LN, mesenteric LN, Peyers patches (combined), SP and bone marrow (from 2 femurs and 2 tibias) were prepared, followed by incubation in ACK lysis buffer (Gibco) for lysis of red blood cells. Cells were resuspended in phenol red-free DMEM (Gibco) with $2 \%$ (vol/vol) FBS at a density of $4 \times 10^{8}$ per $\mathrm{ml}$ for staining. Antibody to CD16/32 (2.4G2; produced 'in-house') was first added for 10 min on ice, before the addition of 'cocktails' of fluorophore-labeled or biotin-labeled monoclonal antibodies (monoclonal antibodies used in Supplemental Table 1) prepared in brilliant stain buffer (BD) 'cocktail' at pretitrated quantities, followed by incubation for 30 min on ice. After samples were washed, biotinlabeled antibodies were detected by incubation for an additional $30 \mathrm{~min}$.

For surface staining of $\lg M$, $\lg G 1$, $\lg G 2 b$, or $\lg A$, non-specific binding was blocked with antiCD16/32 (identified above) for 10 minutes on ice prior to incubation for $30 \mathrm{~min}$ on ice with anti- 
mouse Ig antibodies (Supplemental Table 1). Cells were washed and nonspecific binding was blocked by incubation with $2 \%$ ( $\mathrm{vol} / \mathrm{vol})$ normal mouse and normal rat serum followed by incubation with pre-titrated immunoglobulin specific antibody cocktails prepared in brilliant stain buffer (BD) for 30 min on ice. Cells were washed and resuspended in a solution of phenol redfree DMEM (Gibco) with $2 \%$ (vol/vol) FBS.

For intracellular staining of Blimp-1, Ki-67, and internal $\lg \mathrm{A}$, the surfaces of cells were stained as described above, and cells were labeled with eFluor 780 viability dye (eBioscience). Then cells were fixed, and permeabilized according to the protocol provided in a transcription factor staining kit (eBioscience). Nonspecific intracellular binding was blocked with $2 \%$ mouse and rat serum in permeabilization buffer for 5 minutes on ice. Cells were stained for $30 \mathrm{~min}$ on ice with pre-titrated immunoglobulin specific antibody cocktails. Cells were washed and resuspended in FACs wash (described above).

Single cells were sorted using a four-laser FACS Aria III with FACS Diva 8.0 software equipped with index sorting software (BD Biosciences) for recording of the "index" phenotypic data for each single cell sorted in each well of a 384-well plate. Flow cytometry data were analyzed with FlowJo software (Version 9.9 and 10.6.2, TreeStar).

\section{Elispot}

96 well PVDF-bottomed plates (Millipore) were washed with filtered PBS prior to coating with $\mathrm{NP}^{23}$-BSA (conjugated in-house, $25 \mu \mathrm{g} / \mathrm{mL}$ ) or goat anti-mouse $\operatorname{lgM} / \lg \mathrm{G} / \lg A$ antibody heavy and

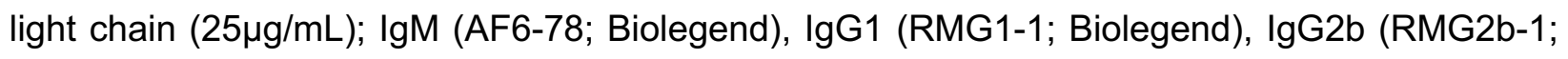
Biolegend), IgG2a (R19-15; BD bioscience), IgG3 (RMG3-1; Biolegend), IgA (RMA-1; Biolegend). Wells were blocked by incubating DMEM media (Gibco) containing 5\% FBS for 1 hour at $37^{\circ} \mathrm{C}$. For bulk Elispot experiments, unstained cells suspended at $4 \times 10^{6}$ cells $/ \mathrm{mL}$ in DMEM (Gibco) with 
FBS ( $5 \% \mathrm{vol} / \mathrm{vol})$ were added to wells at serially titrated quantities $\left(10 \times 10^{4}\right.$ to $1.25 \times 10^{4}$ cells $)$. For single cell sorted Elispot experiments, cells were selectively sorted into 96 well plates using a FACS Aria III with FACS Diva software (BD Biosciences). Plates were incubated at $37^{\circ} \mathrm{C}$ for a minimum of 14 hours, then wells were then washed prior to addition of horse radish peroxidase (HRP) conjugated goat anti-mouse Fc-specific antibodies for 4 hours at room temperature [1:500 dilution for IgM and IgG subclasses, 1:300 for IgA]. HRP conjugated antibodies were all from SouthernBioTech: IgM, IgG, $\lg G 1$, IgG2b, $\lg G 2 a$, IgG3, $\lg A$. Wells were washed and spots detected by adding a filtered solution of $0.2 \mathrm{mg} / \mathrm{mL}$ AEC (3-amino-9-ethylcarbazole; Sigma) in $0.1 \mathrm{M}$ sodium acetate buffer $[\mathrm{pH} 5.0]$ and $0.05 \%$ hydrogen peroxide (Sigma). Wells were washed and air dried for a minimum of 24 hours prior to counting the spots by visual inspection under a stereomicroscope.

\section{qtSEQ single cell RNA sequencing}

The single cell sequencing protocol "qtSEQ" has been previously described $(40,41)$ but will be detailed here in brief. Single cells were index sorted into 384 well plates containing $1 \mathrm{uL}$ of reverse transcription (RT) master mix using a FACS Aria III with FACS Diva software (BD Biosciences) to maintain protein expression with plate well location. The RT master mix per well consisted of:

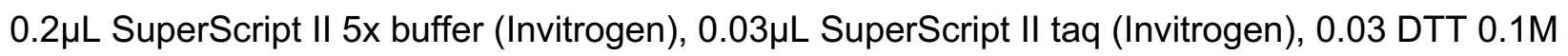
(Invitrogen), $0.03 \mu \mathrm{L}$ RNaseOUT (Invitrogen), $0.012 \mu \mathrm{L}$ of $25 \mu \mathrm{M}$ dNTPs (Invitrogen), $0.19 \mu \mathrm{L}$ RNase Free $\mathrm{H}_{2} \mathrm{O}$ and $0.5 \mu \mathrm{L}$ of oligoDT primer [ $1 \mu \mathrm{M}$ stock] (IDT). Reverse transcription was performed at $42^{\circ} \mathrm{C}$ for 50 minutes followed by heat inactivation at $80^{\circ} \mathrm{C}$ for 10 minutes.

For each plate, all 384 wells were pooled following RT, and excess oligoDT primer were removed using ExoSAP-IT express (Affymetrix) following manufacturers protocol prior to buffer exchange and volume reduction using AMpureXP SPRIselect paramagnetic beads (BeckmanCoulter) at a $0.8 \mathrm{x}$ bead to $1 \mathrm{x}$ library ratio. 
A nested PCR approach was used for targeted gene amplification, gene specific primers (available upon request). PCR 1 was performed in a $60 \mu \mathrm{L}$ reaction: $35 \mu \mathrm{L}$ cDNA library in $\mathrm{H}_{2} \mathrm{O}$,

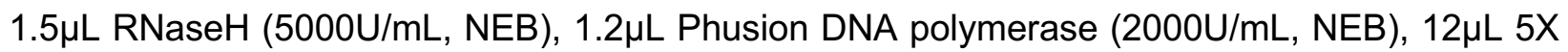
Phusion HF Buffer (NEB), $0.85 \mu \mathrm{L}$ of $25 \mu \mathrm{M}$ dNTPS (Invitrogen), $1.2 \mu \mathrm{L}$ of $100 \mu \mathrm{M}$ RA5-overhang primer (custom made, 5'AAGCAGTGGTGAGTTCTACAGTCCGACGATC 3') and 25nM final concentration for each specific gene targeting external primer using the following thermocycling conditions: $37^{\circ} \mathrm{C}$ for 20 minutes, $98^{\circ} \mathrm{C}$ for 3 minutes, followed by 10 cycles of $95^{\circ} \mathrm{C}$ for 30 seconds, $60^{\circ} \mathrm{C}$ for 3 minutes, $72{ }^{\circ} \mathrm{C}$ for 1 minute and final elongation at $72^{\circ} \mathrm{C}$ for 5 minutes. Removal of excess primers and volume reduction was performed again using AMpureXP SPRIselect beads, at a $0.9 x$ bead to $1 x$ library ratio.

PCR2 was performed in a $20 \mu \mathrm{L}$ reaction: $10 \mu \mathrm{L}$ PCR1 reaction elute, $0.4 \mu \mathrm{L}$ Phusion DNA polymerase (2000U/mL, NEB), $4 \mu \mathrm{L} 5 \mathrm{X}$ Phusion Buffer (NEB), $0.3 \mu \mathrm{L}$ of $25 \mu \mathrm{M}$ dNTPs (Invitrogen), $2 \mu \mathrm{L}$ of $20 \mu \mathrm{M}$ RA5 (custom made, 5' GAGTTCTACAGTCCGACGATC 3'), and 25nM final concentration for each specific gene targeting internal primer using the following thermocycling conditions: $95^{\circ} \mathrm{C}$ for 3 minutes followed by 10 cycles of $95^{\circ} \mathrm{C}$ for 30 seconds, $60^{\circ} \mathrm{C}$ for 3 minutes, $72{ }^{\circ} \mathrm{C}$ for 1 minute and final elongation at $72^{\circ} \mathrm{C}$ for 5 minutes. Removal of excess primers and volume reduction was performed again using AMpureXP SPRIselect beads, at a $0.9 x$ bead to $1 x$ library ratio.

PCR3 was in a $20 \mu \mathrm{L}$ reaction: $10 \mu \mathrm{L}$ PCR2 reaction elute, $0.4 \mu \mathrm{L}$ Phusion DNA polymerase (2000U/mL, NEB), $4 \mu \mathrm{L} 5 \mathrm{X}$ Phusion Buffer (NEB), $0.3 \mu \mathrm{L}$ of $25 \mu \mathrm{M}$ dNTPs (Invitrogen), $2 \mu \mathrm{L}$ of $10 \mu \mathrm{M}$ RP1 primer (Illumina), $2 \mu \mathrm{L}$ of $10 \mu \mathrm{M}$ RPI library specific primer (Illumina) and $1.3 \mu \mathrm{L}$ water using the following thermocycling conditions: $95^{\circ} \mathrm{C}$ for 3 minutes followed by 8 cycles of $95^{\circ} \mathrm{C}$ for 15 seconds, $60^{\circ} \mathrm{C}$ for 30 seconds, $72^{\circ} \mathrm{C}$ for 30 seconds. and final elongation at $72^{\circ} \mathrm{C}$ for 5 minutes. 
Removal of excess primers and volume reduction was performed again using AMpureXP SPRIselect beads, at a $0.7 x$ bead to $1 x$ library ratio and the final library eluted in $20 \mu \mathrm{L} \mathrm{H}_{2} \mathrm{O}$ for quantification and library sequencing preparation.

cDNA library concentration and quality were assessed using an Agilent 2100 Bioanalyzer (Agilent

Technologies) and a Qubit TM 4 Fluorometer (Invitrogen Technologies). Separately labeled cDNA libraries were multiplexed according to the manufacturer's protocol (Illumina, San Diego CA). The libraries were sequenced on an Illumina NextSeq500 sequencer using a paired end sequencing run set as: Read 1: 15 cycles; Index Read 1: 6 cycles; Read 2: 71 cycles.

\section{Single-cell RNA-sequencing analysis:}

Bcl2fastq (Illumina) was used to demultiplex sequencing libraries and assort reads by well barcodes prior to alignment using Bowtie2 to a custom genome consisting of the amplicon regions for the specifically targeted genes used in the experiment based on the murine genome GRCm38.p6, version R97 (Ensembl). HTseq was used for read and UMI reduced tabulation. Quality control discarded wells that contained fewer than 125UMI counts and fewer than 25 unique genes and removed genes that were not expressed in at least 10 different cells. A secondary filter included naïve B cells wells containing 2 of 3 genes (Cd79a, Cd79b, Ptprc) and PC wells containing 2 of 3 genes (Prdm1, Irf4, Xbp1).

Seruat (Version 3(89)) was used for downstream analysis where raw UMI counts were scaled and normalized through log transformation. The Seurat function "FindMarkers" ("negbinom" distribution) was used to find isotype specific differentially expressed genes and Prism V9.0 software (GraphPad) was used to generate volcano plots. The Seurat function "RunUMAP" (using variable features for clustering) was used for transcription based UMAP clustering. The Seurat function "VInPlot" was used for generation of violin plots. Differentially expressed gene 
lists underwent pathway gene ontology (GO) enrichment analysis using PANTHER (version 14.0(90)). Pseudobulk heatmaps were generated using the average gene expression after scaling and normalization for each population using the R function "Pheatmap" (scaling by row enabled).

Integration of surface phenotype data using FlowJo (TreeStar) with transcriptional data from qtSEQ matched well barcodes with index sorting location for UMAP clustering on combined phenotype and transcriptional data using Biovinci (BioTuring Inc., San Diego, CA, USA). The Flowjo function "tSNE" was used for tSNE plot generation using phenotypic data.

\section{Statistics}

The statistical tests and methods, number of samples, and number of cells or genes are indicated in the figure legends. Statistics computed with $\mathrm{R}$ software detailed above. Mean values, s.e.m. values, and unpaired Students t-tests were calculated and graphed with Prism v9.0 software (GraphPad). A P value of less than 0.05 was considered statistically significant.

\section{Code and Data availability.}

All customized R codes used for data analysis and raw and processed data files for the scRNAseq analysis in the study will be provided upon request without restriction.

\section{Acknowledgements:}

This work was supported by the US National Institutes of Health (AI047231, AI040215 and AI071182) and Bill \& Melinda Gates Foundation (BMGF OPP1154835) to M.G.M.-W.

Author Contributions: B.W.H, A.G.S, L.J.M-W, and M.G.M-W designed and developed single cell qtSEQ, B.W.H, A.G.S, K.B.M, A.M.R, L.J.M-W, and M.G.M-W designed and performed 
bioRxiv preprint doi: https://doi.org/10.1101/2021.08.31.458458; this version posted September 1, 2021. The copyright holder for this preprint (which was not certified by peer review) is the author/funder. All rights reserved. No reuse allowed without permission.

experiments, B.W.H, L.J.M-W, and M.G.M-W designed the study, analyzed data and wrote the paper.

Competing interests: The authors declare no competing financial interests. 


\section{REFERENCES}

1. M. McHeyzer-Williams, S. Okitsu, N. Wang, L. McHeyzer-Williams, Molecular programming of B cell memory. Nat Rev Immunol 12, 24-34 (2011).

2. S. Crotty, T follicular helper cell differentiation, function, and roles in disease. Immunity $\mathbf{4 1 ,}$ 529-542 (2014).

3. C. M. Snapper, W. E. Paul, Interferon-gamma and B cell stimulatory factor-1 reciprocally regulate Ig isotype production. Science 236, 944-947 (1987).

4. S. G. Tangye, A. Ferguson, D. T. Avery, C. S. Ma, P. D. Hodgkin, Isotype switching by human B cells is division-associated and regulated by cytokines. J Immunol 169, 4298-4306 (2002).

5. J. A. Roco, L. Mesin, S. C. Binder, C. Nefzger, P. Gonzalez-Figueroa, P. F. Canete et al., Class-Switch Recombination Occurs Infrequently in Germinal Centers. Immunity 51, 337350 e337 (2019).

6. J. J. O'Shea, W. E. Paul, Mechanisms underlying lineage commitment and plasticity of helper CD4+ T cells. Science 327, 1098-1102 (2010).

7. E. Vivier, D. Artis, M. Colonna, A. Diefenbach, J. P. Di Santo, G. Eberl, S. Koyasu, R. M. Locksley, A. N. J. McKenzie, R. E. Mebius, F. Powrie, H. Spits, Innate Lymphoid Cells: 10 Years On. Cell 174, 1054-1066 (2018).

8. N. S. Wang, L. J. McHeyzer-Williams, S. L. Okitsu, T. P. Burris, S. L. Reiner, M. G. McHeyzerWilliams, Divergent transcriptional programming of class-specific B cell memory by T-bet and RORalpha. Nat Immunol 13, 604-611 (2012).

9. B. W. Higgins, L. J. McHeyzer-Williams, M. G. McHeyzer-Williams, Programming IsotypeSpecific Plasma Cell Function. Trends Immunol 40, 345-357 (2019).

10. F. Nimmerjahn, A. Lux, H. Albert, M. Woigk, C. Lehmann, D. Dudziak, P. Smith, J. V. Ravetch, FcgammaRIV deletion reveals its central role for lgG2a and lgG2b activity in vivo. Proc Natl Acad Sci U S A 107, 19396-19401 (2010). 
11. C. M. Karsten, M. K. Pandey, J. Figge, R. Kilchenstein, P. R. Taylor, M. Rosas et al., Antiinflammatory activity of IgG1 mediated by Fc galactosylation and association of FcgammaRIIB and dectin-1. Nat Med 18, 1401-1406 (2012).

12. R. T. Strait, M. T. Posgai, A. Mahler, N. Barasa, C. O. Jacob, J. Kohl, M. Ehlers, K. Stringer, S. K. Shanmukhappa, D. Witte, M. M. Hossain, M. Khodoun, A. B. Herr, F. D. Finkelman, IgG1 protects against renal disease in a mouse model of cryoglobulinaemia. Nature 517, 501-504 (2015).

13. S. Fagarasan, S. Kawamoto, O. Kanagawa, K. Suzuki, Adaptive Immune Regulation in the Gut: T Cell-Dependent and T Cell-Independent IgA Synthesis. Annual Review of Immunology, Vol 28 28, 243-273 (2010).

14. J. J. Bunker, T. M. Flynn, J. C. Koval, D. G. Shaw, M. Meisel, B. D. McDonald, I. E. Ishizuka, A. L. Dent, P. C. Wilson, B. Jabri, D. A. Antonopoulos, A. Bendelac, Innate and Adaptive Humoral Responses Coat Distinct Commensal Bacteria with Immunoglobulin A. Immunity 43, 541-553 (2015).

15. J. J. Bunker, S. A. Erickson, T. M. Flynn, C. Henry, J. C. Koval, M. Meisel, B. Jabri, D. A. Antonopoulos, P. C. Wilson, A. Bendelac, Natural polyreactive IgA antibodies coat the intestinal microbiota. Science 358, (2017).

16. M. Matsumoto, A. Baba, T. Yokota, H. Nishikawa, Y. Ohkawa, H. Kayama, A. Kallies, S. L. Nutt, S. Sakaguchi, K. Takeda, T. Kurosaki, Y. Baba, Interleukin-10-Producing Plasmablasts Exert Regulatory Function in Autoimmune Inflammation. Immunity 41, 1040-1051 (2014).

17. P. Blanc, L. Moro-Sibilot, L. Barthly, F. Jagot, S. This, S. de Bernard, L. Buffat, S. Dussurgey, R. Colisson, E. Hobeika, T. Fest, M. Taillardet, O. Thaunat, A. Sicard, P. Mondiere, L. Genestier, S. L. Nutt, T. Defrance, Mature IgM-expressing plasma cells sense antigen and develop competence for cytokine production upon antigenic challenge. Nat Commun 7, 13600 (2016). 
18. J. H. Fritz, O. L. Rojas, N. Simard, D. D. McCarthy, S. Hapfelmeier, S. Rubino, S. J. Robertson, M. Larijani, J. Gosselin, Ivanov, II, A. Martin, R. Casellas, D. J. Philpott, S. E. Girardin, K. D. McCoy, A. J. Macpherson, C. J. Paige, J. L. Gommerman, Acquisition of a multifunctional IgA+ plasma cell phenotype in the gut. Nature 481, 199-203 (2011).

19. P. Shen, T. Roch, V. Lampropoulou, R. A. O'Connor, U. Stervbo, E. Hilgenberg et al., IL-35producing B cells are critical regulators of immunity during autoimmune and infectious diseases. Nature 507, 366-370 (2014).

20. D. A. Bermejo, S. W. Jackson, M. Gorosito-Serran, E. V. Acosta-Rodriguez, M. C. AmezcuaVesely, B. D. Sather, A. K. Singh, S. Khim, J. Mucci, D. Liggitt, O. Campetella, M. Oukka, A. Gruppi, D. J. Rawlings, Trypanosoma cruzi trans-sialidase initiates a program independent of the transcription factors ROR gamma t and Ahr that leads to IL-17 production by activated B cells. Nat Immunol 14, 514-522 (2013).

21. J. Tellier, W. Shi, M. Minnich, Y. Liao, S. Crawford, G. K. Smyth, A. Kallies, M. Busslinger, S. L. Nutt, Blimp-1 controls plasma cell function through the regulation of immunoglobulin secretion and the unfolded protein response. Nat Immunol 17, 323-330 (2016).

22. M. Minnich, H. Tagoh, P. Bonelt, E. Axelsson, M. Fischer, B. Cebolla, A. Tarakhovsky, S. L. Nutt, M. Jaritz, M. Busslinger, Multifunctional role of the transcription factor Blimp-1 in coordinating plasma cell differentiation. Nat Immunol 17, 331-343 (2016).

23. M. Shapiro-Shelef, K. I. Lin, L. J. McHeyzer-Williams, J. Liao, M. G. McHeyzer-Williams, K. Calame, Blimp-1 is required for the formation of immunoglobulin secreting plasma cells and pre-plasma memory B cells. Immunity 19, 607-620 (2003).

24. K. Ochiai, M. Maienschein-Cline, G. Simonetti, J. Chen, R. Rosenthal, R. Brink, A. S. Chong, U. Klein, A. R. Dinner, H. Singh, R. Sciammas, Transcriptional regulation of germinal center B and plasma cell fates by dynamical control of IRF4. Immunity 38, 918-929 (2013). 
25. A. M. Reimold, N. N. Iwakoshi, J. Manis, P. Vallabhajosyula, E. Szomolanyi-Tsuda, E. M. Gravallese, D. Friend, M. J. Grusby, F. Alt, L. H. Glimcher, Plasma cell differentiation requires the transcription factor XBP-1. Nature 412, 300-307 (2001).

26. U. Klein, S. Casola, G. Cattoretti, Q. Shen, M. Lia, T. Mo, T. Ludwig, K. Rajewsky, R. DallaFavera, Transcription factor IRF4 controls plasma cell differentiation and class-switch recombination. Nat Immunol 7, 773-782 (2006).

27. R. Sciammas, A. L. Shaffer, J. H. Schatz, H. Zhao, L. M. Staudt, H. Singh, Graded expression of interferon regulatory factor-4 coordinates isotype switching with plasma cell differentiation. Immunity 25, 225-236 (2006).

28. S. Carotta, S. N. Willis, J. Hasbold, M. Inouye, S. H. M. Pang, D. Emslie, A. Light, M. Chopin, W. Shi, H. S. Wang, H. C. Morse, D. M. Tarlinton, L. M. Corcoran, P. D. Hodgkin, S. L. Nutt, The transcription factors IRF8 and PU.1 negatively regulate plasma cell differentiation. J Exp Med 211, 2169-2181 (2014).

29. W. Shi, Y. Liao, S. N. Willis, N. Taubenheim, M. Inouye, D. M. Tarlinton, G. K. Smyth, P. D. Hodgkin, S. L. Nutt, L. M. Corcoran, Transcriptional profiling of mouse B cell terminal differentiation defines a signature for antibody-secreting plasma cells. Nat Immunol 16, 663673 (2015).

30. H. Qi, T follicular helper cells in space-time. Nat Rev Immunol 16, 612-625 (2016).

31. F. J. Weisel, G. V. Zuccarino-Catania, M. Chikina, M. J. Shlomchik, A Temporal Switch in the Germinal Center Determines Differential Output of Memory B and Plasma Cells. Immunity 44, 116-130 (2016).

32. C. Viant, G. H. J. Weymar, A. Escolano, S. Chen, H. Hartweger, M. Cipolla, A. Gazumyan, M. C. Nussenzweig, Antibody Affinity Shapes the Choice between Memory and Germinal Center B Cell Fates. Cell 183, 1298-1311 e1211 (2020).

33. W. Ise, K. Fujii, K. Shiroguchi, A. Ito, K. Kometani, K. Takeda, E. Kawakami, K. Yamashita, K. Suzuki, T. Okada, T. Kurosaki, T Follicular Helper Cell-Germinal Center B Cell Interaction 
Strength Regulates Entry into Plasma Cell or Recycling Germinal Center Cell Fate. Immunity 48, 702-715 (2018).

34. S. L. Nutt, P. D. Hodgkin, D. M. Tarlinton, L. M. Corcoran, The generation of antibodysecreting plasma cells. Nat Rev Immunol 15, 160-171 (2015).

35. M. G. McHeyzer-Williams, G. J. Nossal, P. A. Lalor, Molecular characterization of single memory B cells. Nature 350, 502-505 (1991).

36. L. J. McHeyzer-Williams, P. J. Milpied, S. L. Okitsu, M. G. McHeyzer-Williams, Classswitched memory B cells remodel BCRs within secondary germinal centers. Nat Immunol 16, 296-305 (2015).

37. D. J. Driver, L. J. McHeyzer-Williams, M. Cool, D. B. Stetson, M. G. McHeyzer-Williams, Development and maintenance of a B220- memory B cell compartment. J Immunol 167, 1393-1405 (2001).

38. N. Pelletier, L. J. McHeyzer-Williams, K. A. Wong, E. Urich, N. Fazilleau, M. G. McHeyzerWilliams, Plasma cells negatively regulate the follicular helper T cell program. Nat Immunol $11,1110-1118$ (2010).

39. C. R. Nowosad, L. Mesin, T. B. R. Castro, C. Wichmann, G. P. Donaldson, T. Araki, A. Schiepers, A. A. K. Lockhart, A. M. Bilate, D. Mucida, G. D. Victora, Tunable dynamics of B cell selection in gut germinal centres. Nature 588, 321-326 (2020).

40. A. G. Shuparski, B. W. Higgins, K. B. Miller, C. R. Dufaud, A. M. Robinson, K. Dueker, L. J. McHeyzer-Williams, M. G. McHeyzer-Williams, Single cell qtSEQ: Cell-indexed quantitative and targeted RNA sequencing for sorted rare lymphocyte subpopulations. BioRxiv, BIORXIV/2021/458455 (2021).

41. C. R. Dufaud, A. G. Shuparski, B. W. Higgins, L. J. McHeyzer-Williams, M. G. McHeyzerWilliams, PD-1 checkpoint blockade disrupts CD4 T cell regulated adaptive B cell tolerance to foreign antigen. BioRxiv, 2021.06.10.447979; doi: https://doi.org/10.1101/2021.06.10.447979 (2021). 
42. G. Ledergor, A. Weiner, M. Zada, S. Y. Wang, Y. C. Cohen, M. E. Gatt et al., Single cell dissection of plasma cell heterogeneity in symptomatic and asymptomatic myeloma. Nat Med 24, 1867-1876 (2018).

43. W. Y. Lam, A. Jash, C. H. Yao, L. D'Souza, R. Wong, R. M. Nunley, G. P. Meares, G. J. Patti, D. Bhattacharya, Metabolic and Transcriptional Modules Independently Diversify Plasma Cell Lifespan and Function. Cell Rep 24, 2479-2492 (2018).

44. M. G. McHeyzer-Williams, M. J. McLean, G. J. Nossal, P. A. Lalor, The dynamics of T celldependent B cell responses in vivo. Immunol Cell Biol 70 ( Pt 2), 119-127 (1992).

45. M. G. McHeyzer-Williams, M. J. McLean, P. A. Lalor, G. J. Nossal, Antigen-driven B cell differentiation in vivo. J Exp Med 178, 295-307 (1993).

46. L. J. McHeyzer-Williams, M. Cool, M. G. McHeyzer-Williams, Antigen-specific B cell memory: expression and replenishment of a novel b220(-) memory b cell compartment. $J$ Exp Med $191,1149-1166$ (2000).

47. L. J. McHeyzer-Williams, M. G. McHeyzer-Williams, Developmentally distinct Th cells control plasma cell production in vivo. Immunity 20, 231-242 (2004).

48. L. Zhou, J. E. Lopes, M. M. Chong, Ivanov, II, R. Min, G. D. Victora, Y. Shen, J. Du, Y. P. Rubtsov, A. Y. Rudensky, S. F. Ziegler, D. R. Littman, TGF-beta-induced Foxp3 inhibits $\mathrm{T}(\mathrm{H}) 17$ cell differentiation by antagonizing RORgammat function. Nature 453, 236-240 (2008).

49. F. Y. Jin, C. Nathan, D. Radzioch, A. Ding, Secretory leukocyte protease inhibitor: a macrophage product induced by and antagonistic to bacterial lipopolysaccharide. Cell $\mathbf{8 8}$, 417-426 (1997).

50. B. K. Choi, H. W. Lee, The Murine CD137/CD137 Ligand Signalosome: A Signal Platform Generating Signal Complexity. Front Immunol 11, 553715 (2020). 
51. Z. Shulman, A. D. Gitlin, J. S. Weinstein, B. Lainez, E. Esplugues, R. A. Flavell, J. E. Craft, M. C. Nussenzweig, Dynamic signaling by T follicular helper cells during germinal center B cell selection. Science 345, 1058-1062 (2014).

52. G. D. Victora, T. A. Schwickert, D. R. Fooksman, A. O. Kamphorst, M. Meyer-Hermann, M. L. Dustin, M. C. Nussenzweig, Germinal center dynamics revealed by multiphoton microscopy with a photoactivatable fluorescent reporter. Cell 143, 592-605 (2010).

53. A. D. Gitlin, L. von Boehmer, A. Gazumyan, Z. Shulman, T. Y. Oliveira, M. C. Nussenzweig, Independent Roles of Switching and Hypermutation in the Development and Persistence of B Lymphocyte Memory. Immunity 44, 769-781 (2016).

54. R. Shinnakasu, T. Inoue, K. Kometani, S. Moriyama, Y. Adachi, M. Nakayama, Y. Takahashi, H. Fukuyama, T. Okada, T. Kurosaki, Regulated selection of germinal-center cells into the memory B cell compartment. Nat Immunol 17, 861-869 (2016).

55. N. J. Krautler, D. Suan, D. Butt, K. Bourne, J. R. Hermes, T. D. Chan, C. Sundling, W. Kaplan, P. Schofield, J. Jackson, A. Basten, D. Christ, R. Brink, Differentiation of germinal center B cells into plasma cells is initiated by high-affinity antigen and completed by Tfh cells. $J$ Exp Med 214, 1259-1267 (2017).

56. C. H. Rozanski, R. Arens, L. M. Carlson, J. Nair, L. H. Boise, A. A. Chanan-Khan, S. P. Schoenberger, K. P. Lee, Sustained antibody responses depend on CD28 function in bone marrow-resident plasma cells. J Exp Med 208, 1435-1446 (2011).

57. S. Chevrier, C. Genton, A. Kallies, A. Karnowski, L. A. Otten, B. Malissen, M. Malissen, M. Botto, L. M. Corcoran, S. L. Nutt, H. Acha-Orbea, CD93 is required for maintenance of antibody secretion and persistence of plasma cells in the bone marrow niche. $P$ Natl Acad Sci USA 106, 3895-3900 (2009).

58. W. Y. Lam, A. M. Becker, K. M. Kennerly, R. Wong, J. D. Curtis, E. M. Llufrio, K. S. McCommis, J. Fahrmann, H. A. Pizzato, R. M. Nunley, J. Lee, M. J. Wolfgang, G. J. Patti, B. 
N. Finck, E. L. Pearce, D. Bhattacharya, Mitochondrial Pyruvate Import Promotes Long-Term Survival of Antibody-Secreting Plasma Cells. Immunity 45, 60-73 (2016).

59. A. Glatman Zaretsky, C. Konradt, F. Depis, J. B. Wing, R. Goenka, D. G. Atria et al., T Regulatory Cells Support Plasma Cell Populations in the Bone Marrow. Cell Rep 18, 19061916 (2017).

60. A. C. Lino, V. D. Dang, V. Lampropoulou, A. Welle, J. Joedicke, J. Pohar et al., LAG-3 Inhibitory Receptor Expression Identifies Immunosuppressive Natural Regulatory Plasma Cells. Immunity 49, 120-133 e129 (2018).

61. E. C. Rosser, C. Mauri, Regulatory B cells: origin, phenotype, and function. Immunity 42 , 607-612 (2015).

62. S. Kawamoto, T. H. Tran, M. Maruya, K. Suzuki, Y. Doi, Y. Tsutsui, L. M. Kato, S. Fagarasan, The inhibitory receptor PD-1 regulates IgA selection and bacterial composition in the gut. Science 336, 485-489 (2012).

63. P. Bergqvist, A. Stensson, L. Hazanov, A. Holmberg, J. Mattsson, R. Mehr, M. Bemark, N. Y. Lycke, Re-utilization of germinal centers in multiple Peyer's patches results in highly synchronized, oligoclonal, and affinity-matured gut IgA responses. Mucosal Immunol 6, 122135 (2013).

64. H. Chen, Y. Zhang, A. Y. Ye, Z. Du, M. Xu, C. S. Lee, J. K. Hwang, N. Kyritsis, Z. Ba, D. Neuberg, D. R. Littman, F. W. Alt, BCR selection and affinity maturation in Peyer's patch germinal centres. Nature 582, 421-425 (2020).

65. A. Biram, A. Stromberg, E. Winter, L. Stoler-Barak, R. Salomon, Y. Addadi, R. Dahan, G. Yaari, M. Bemark, Z. Shulman, BCR affinity differentially regulates colonization of the subepithelial dome and infiltration into germinal centers within Peyer's patches. Nat Immunol 20, 482-492 (2019). 
66. K. L. Good-Jacobson, C. G. Szumilas, L. Chen, A. H. Sharpe, M. M. Tomayko, M. J. Shlomchik, PD-1 regulates germinal center B cell survival and the formation and affinity of long-lived plasma cells. Nat Immunol 11, 535-542 (2010).

67. T. Doi, T. Kanai, Y. Mikami, T. Sujino, L. Jun, Y. Ono, A. Hayashi, T. Hibi, IgA plasma cells express the negative regulatory co-stimulatory molecule programmed cell death 1 ligand and have a potential tolerogenic role in the intestine. Biochem Biophys Res Commun 425, 918923 (2012).

68. C. Neumann, J. Blume, U. Roy, P. P. Teh, A. Vasanthakumar, A. Beller et al., c-Mafdependent Treg cell control of intestinal TH17 cells and IgA establishes host-microbiota homeostasis. Nat Immunol 20, 471-481 (2019).

69. L. Drujont, A. Lemoine, A. Moreau, G. Bienvenu, M. Lancien, T. Cens, F. Guillot, G. Beriou, L. Bouchet-Delbos, H. J. Fehling, E. Chiffoleau, A. B. Nicot, P. Charnet, J. C. Martin, R. Josien, M. C. Cuturi, C. Louvet, ROR gamma $t(+)$ cells selectively express redundant cation channels linked to the Golgi apparatus. Sci Rep-Uk 6, (2016).

70. G. Meyer Zu Horste, D. Przybylski, M. A. Schramm, C. Wang, A. Schnell, Y. Lee, R. Sobel, A. Regev, V. K. Kuchroo, Fas Promotes T Helper 17 Cell Differentiation and Inhibits T Helper 1 Cell Development by Binding and Sequestering Transcription Factor STAT1. Immunity 48, 556-569 e557 (2018).

71. C. Wang, S. G. Kang, J. Lee, Z. Sun, C. H. Kim, The roles of CCR6 in migration of Th17 cells and regulation of effector T-cell balance in the gut. Mucosal Immunol 2, 173-183 (2009).

72. K. Hirota, J. E. Turner, M. Villa, J. H. Duarte, J. Demengeot, O. M. Steinmetz, B. Stockinger, Plasticity of Th17 cells in Peyer's patches is responsible for the induction of T cell-dependent IgA responses. Nat Immunol 14, 372-379 (2013).

73. G. J. Martinez, R. I. Nurieva, X. O. Yang, C. Dong, Regulation and function of proinflammatory TH17 cells. Ann N Y Acad Sci 1143, 188-211 (2008). 
74. E. Jang, W. S. Cho, Y. K. Oh, M. L. Cho, J. M. Kim, D. J. Paik, J. Youn, Splenic Long-Lived Plasma Cells Promote the Development of Follicular Helper T Cells during Autoimmune Responses. J Immunol 196, 1026-1035 (2016).

75. J. I. Ellyard, D. T. Avery, T. G. Phan, N. J. Hare, P. D. Hodgkin, S. G. Tangye, Antigenselected, immunoglobulin-secreting cells persist in human spleen and bone marrow. Blood 103, 3805-3812 (2004).

76. M. Bemark, H. Hazanov, A. Strömberg, R. Komban, J. Holmqvist, S. Köster, J. Mattsson, P. Sikora, R. Mehr, N. Y. Lycke, Limited clonal relatedness between gut IgA plasma cells and memory B cells after oral immunization. Nat Commun 7, 12698 (2016).

77. A. Lemke, M. Kraft, K. Roth, R. Riedel, D. Lammerding, A. E. Hauser, Long-lived plasma cells are generated in mucosal immune responses and contribute to the bone marrow plasma cell pool in mice. Mucosal Immunol 9, 83-97 (2016).

78. R. Iversen, O. Snir, M. Stensland, J. E. Kroll, O. Steinsbo, I. R. Korponay-Szabo, K. E. A. Lundin, G. A. de Souza, L. M. Sollid, Strong Clonal Relatedness between Serum and Gut IgA despite Different Plasma Cell Origins. Cell Reports 20, 2357-2367 (2017).

79. F. Horns, C. Vollmers, D. Croote, S. F. Mackey, G. E. Swan, C. L. Dekker, M. M. Davis, S. R. Quake, Lineage tracing of human B cells reveals the in vivo landscape of human antibody class switching. Elife 5, e16578 (2016).

80. D. R. Glass, A. G. Tsai, J. P. Oliveria, F. J. Hartmann, S. C. Kimmey, A. A. Calderon, L. Borges, M. C. Glass, L. E. Wagar, M. M. Davis, S. C. Bendall, An Integrated Multi-omic Single-Cell Atlas of Human B Cell Identity. Immunity 53, 217-232 e215 (2020).

81. H. W. King, N. Orban, J. C. Riches, A. J. Clear, G. Warnes, S. A. Teichmann, L. K. James, Single-cell analysis of human B cell maturation predicts how antibody class switching shapes selection dynamics. Sci Immunol 6, (2021).

82. D. Croote, S. Darmanis, K. C. Nadeau, S. R. Quake, High-affinity allergen-specific human antibodies cloned from single IgE B cell transcriptomes. Science 362, 1306-1309 (2018). 
83. M. A. Dimopoulos, D. Dytfeld, S. Grosicki, P. Moreau, N. Takezako, M. Hori, X. Leleu, R. LeBlanc, K. Suzuki, M. S. Raab, P. G. Richardson, M. Popa McKiver, Y. M. Jou, S. G. Shelat, M. Robbins, B. Rafferty, J. San-Miguel, Elotuzumab plus Pomalidomide and Dexamethasone for Multiple Myeloma. N Engl J Med 379, 1811-1822 (2018).

84. E. Borsi, G. Perrone, C. Terragna, M. Martello, A. F. Dico, G. Solaini, A. Baracca, G. Sgarbi, G. Pasquinelli, S. Valente, E. Zamagni, P. Tacchetti, G. Martinelli, M. Cavo, Hypoxia inducible factor-1 alpha as a therapeutic target in multiple myeloma. Oncotarget 5, 17791792 (2014).

85. T. C. Cheong, M. Compagno, R. Chiarle, Editing of mouse and human immunoglobulin genes by CRISPR-Cas9 system. Nat Commun 7, (2016).

86. J. E. Voss, A. Gonzalez-Martin, R. Andrabi, R. P. Fuller, B. Murrell, L. E. McCoy, K. Porter, D. Huang, W. Li, D. Sok, K. Le, B. Briney, M. Chateau, G. Rogers, L. Hangartner, A. J. Feeney, D. Nemazee, P. Cannon, D. R. Burton, Reprogramming the antigen specificity of B cells using genome-editing technologies. Elife 8, (2019).

87. V. Greiner, R. Bou Puerto, S. Liu, C. Herbel, E. M. Carmona, M. S. Goldberg, CRISPRMediated Editing of the B Cell Receptor in Primary Human B Cells. iScience 12, 369-378 (2019).

88. K. Kometani, R. Nakagawa, R. Shinnakasu, T. Kaji, A. Rybouchkin, S. Moriyama, K. Furukawa, H. Koseki, T. Takemori, T. Kurosaki, Repression of the transcription factor Bach2 contributes to predisposition of IgG1 memory B cells toward plasma cell differentiation. Immunity 39, 136-147 (2013).

89. T. Stuart, A. Butler, P. Hoffman, C. Hafemeister, E. Papalexi, W. M. Mauck, 3rd, Y. Hao, M. Stoeckius, P. Smibert, R. Satija, Comprehensive Integration of Single-Cell Data. Cell 177, 1888-1902 e1821 (2019). 
90. H. Mi, A. Muruganujan, X. Huang, D. Ebert, C. Mills, X. Guo, P. D. Thomas, Protocol Update for large-scale genome and gene function analysis with the PANTHER classification system (v.14.0). Nat Protoc 14, 703-721 (2019). 


\section{Figure 1}
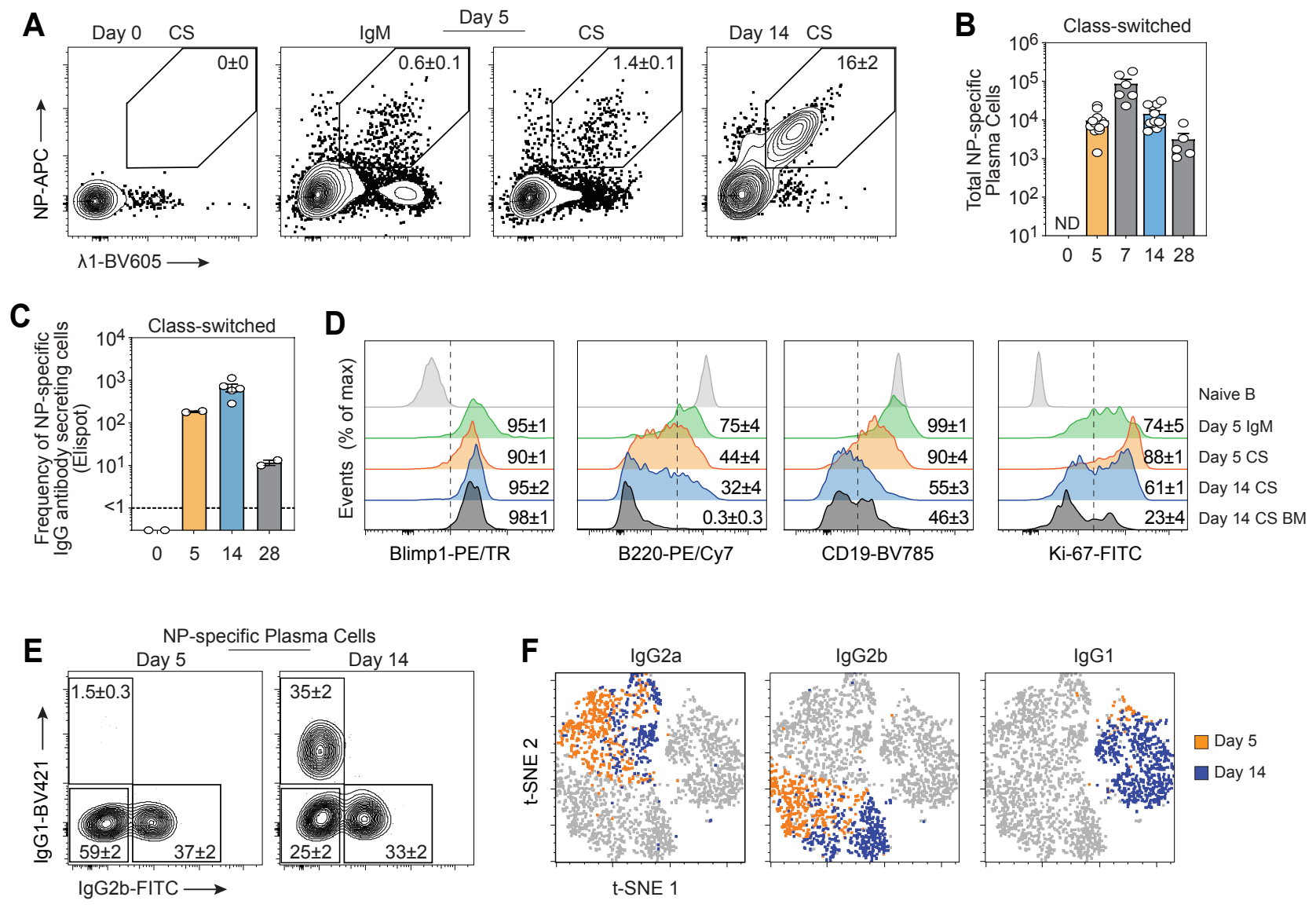

$\square$ Day 5

$\square$ Day 14 
Figure 1: Antigen-driven segregation of isotype-specific PC differentiation. (A) Flow cytometry of class switched $\left(\mathrm{CS}, \lg \mathrm{D}^{-} \lg \mathrm{M}^{-}\right)$or $\lg \mathrm{M}^{+}\left(\lg \mathrm{D}-\lg \mathrm{M}^{+}\right)$antigen-specific $\left(\mathrm{NP}^{+} \lambda 1^{+}\right)$plasma cells $\left(\mathrm{PC}, \mathrm{Gr}^{-}{ }^{-} \mathrm{CD} 3 \mathrm{e}^{-} \lg \mathrm{D}^{-} \mathrm{CD} 138^{+}\right)$from draining lymph nodes $(\mathrm{LN})$ before and 5 and 14 days after primary immunization with NP-KLH. Numbers in outlined areas indicate percent $\mathrm{NP}^{+} \lambda 1^{+}(\operatorname{mean} \pm$ s.e.m.). (B) Quantification CS NP ${ }^{+} \lambda 1^{+}$PCs from the dLN after primary immunization. ND, not detected. (C) Count per million frequency of $\mathrm{CS} \mathrm{NP}^{+} \lambda 1^{+} \mathrm{PCs}$ detected by Elispot at times (below graph) after immunization. (D) Intracellular expression of Blimp-1 and Ki-67 and surface expression of CD19 and $\mathrm{B} 220$ in $\mathrm{NP}^{+} \lambda 1^{+} \mathrm{PCs}$ compared to naive $\mathrm{B}$ cells $\left(\mathrm{CD}_{19}{ }^{+} \lg \mathrm{D}^{+} \lg \mathrm{M}^{+} \lambda 1^{+} \mathrm{CD} 138^{-} \mathrm{NP}^{-} \mathrm{Gr} 1^{-} \mathrm{CD} 3 \mathrm{e}^{-}\right)$. Numbers indicate positive percentage expressing (mean \pm s.e.m.). (E) Flow cytometry of $\operatorname{lgG} 1^{+}, \lg G 2 b^{+}$and $\lg G 2 a^{+}\left(\lg G 1^{-} \lg G 2 b^{-}\right) N P^{+} \lambda 1^{+} P C s$ from d5 and d14. (F) Overlay of each PC class as shown in E (d5 in orange and d14 in blue) onto a tSNE (t-distributed stochastic neighbor embedding) plot generated using surface phenotype. (A, B; $d 0, d 5, d 14 n=12, d 7 n=6, d 28 n=5$ mice per time point. C; $2-5$ mice per time point; mean \pm s.e.m. D; mean \pm s.e.m., $n=5$ mice. E; mean \pm s.e.m., $d 5 n=23$, d14 $n=18$ mice. $F ; n=1534$ cells at $d 5, n=1189$ cells at $d 14$ taken from $1 \mathrm{dLN}$ at each time point, representative of $n=12$ mice) 
Figure 2
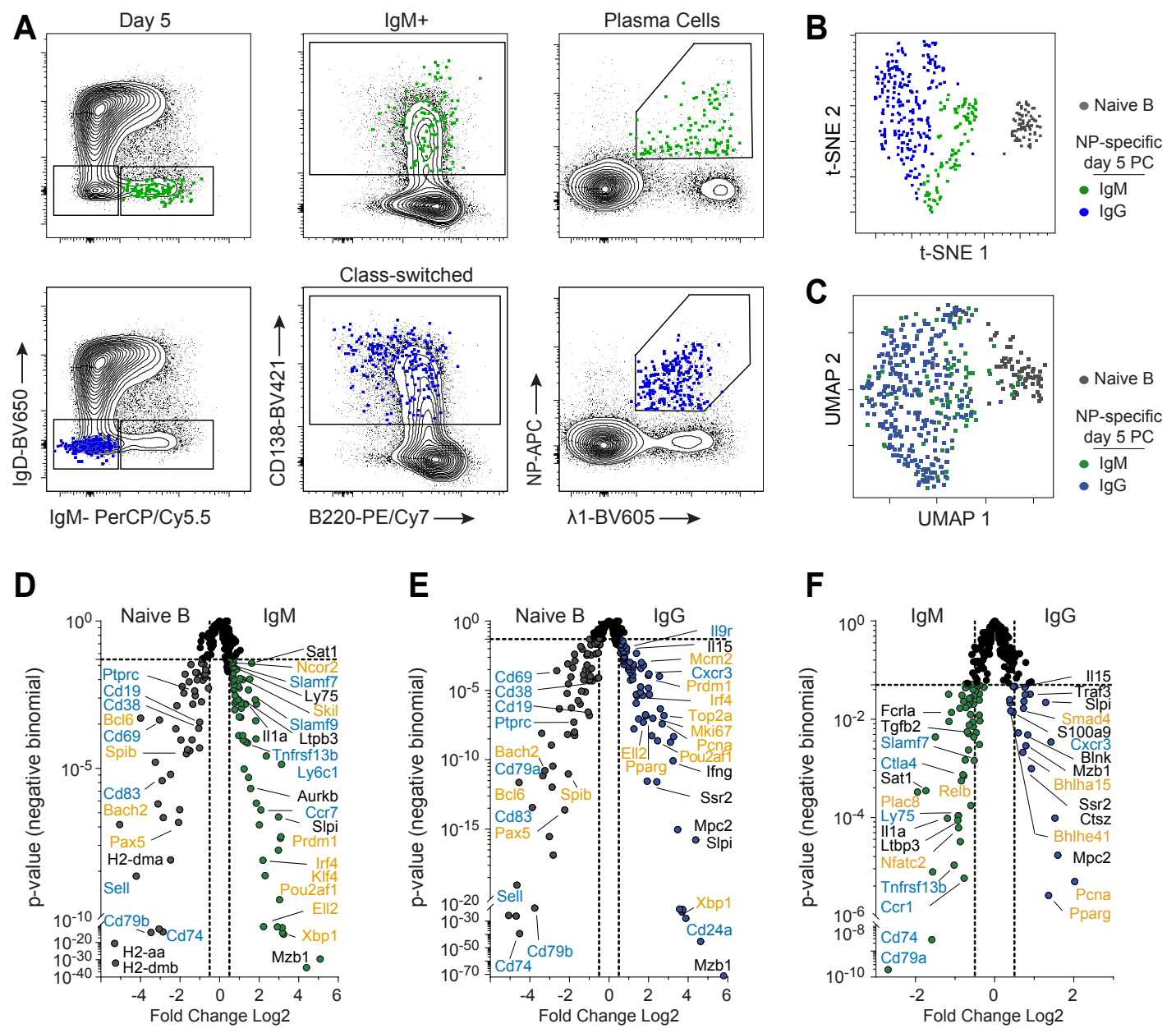

G

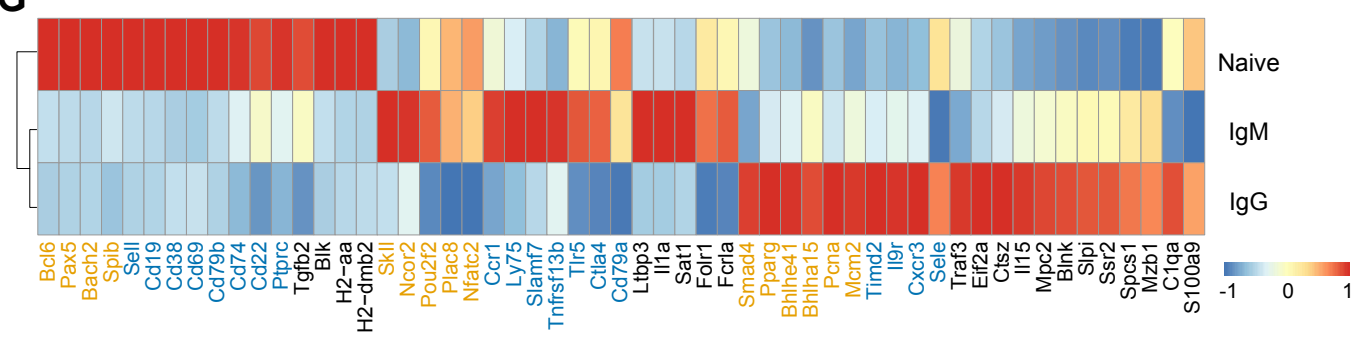


Figure 2: Divergent IgM and IgG effector PC Programs. (A) Flow cytometry of index sorted antigen specific $\operatorname{lgM}^{+}$(top, in green) and $\operatorname{lgG}^{+}$(bottom, in blue) PCs overlaid on contour plots of total populations. (B) Dimensional reduction on index sorted PCs based on surface phenotype using tSNE (t-distributed stochastic neighbor embedding) or (C) based on gene expression distribution using uniform manifold approximation and projection (UMAP). (D) Differences in gene expression plotted by statistical significance and presented as volcano plots comparing naive B cells $\left(\mathrm{CD}^{1} 9^{+} \lg \mathrm{D}^{+} \operatorname{IgM}^{+} \lambda 1^{+} \mathrm{CD} 138-\mathrm{NP}^{-} \mathrm{Gr}^{-}{ }^{-} \mathrm{CD} 3 \mathrm{e}^{-}\right)$to antigen specific $\operatorname{lgM}^{+} \mathrm{PCs}$ to $(\mathrm{E}) \operatorname{lgG}^{+} \mathrm{PCs}$, or between (F) $\operatorname{lgM}^{+}$and $\operatorname{lgG}^{+}$PCs. (G) Pseudobulk heatmap representation of differentially expressed genes from D-F using average gene expression values in each cell population. The color scale is based on z-score distribution. For D-G, index sorted cells $n=109 \operatorname{lgM}^{+}, 269 \operatorname{lgG}^{+}$, 73 naive B cells; genes labeled in orange represent transcriptional modifiers translocating to or residing in the nucleus, genes labeled in teal represent surface/membrane genes and genes in black represent cytosolic and secreted genes. 
Figure 3
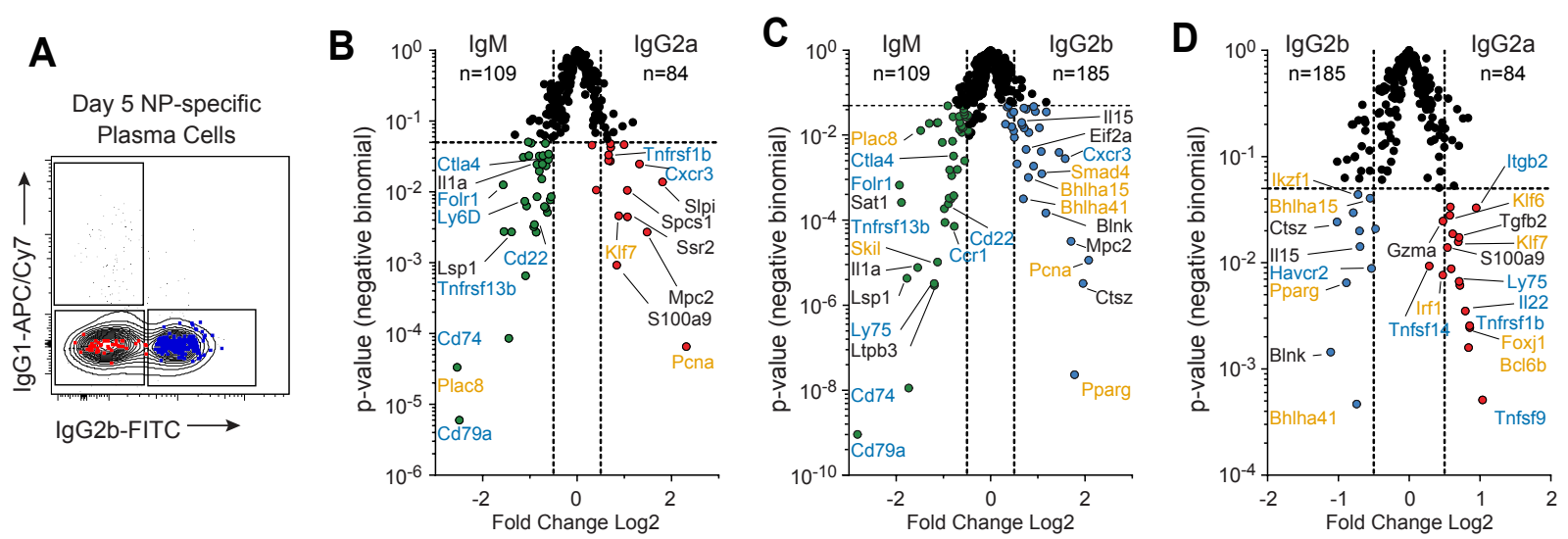

E
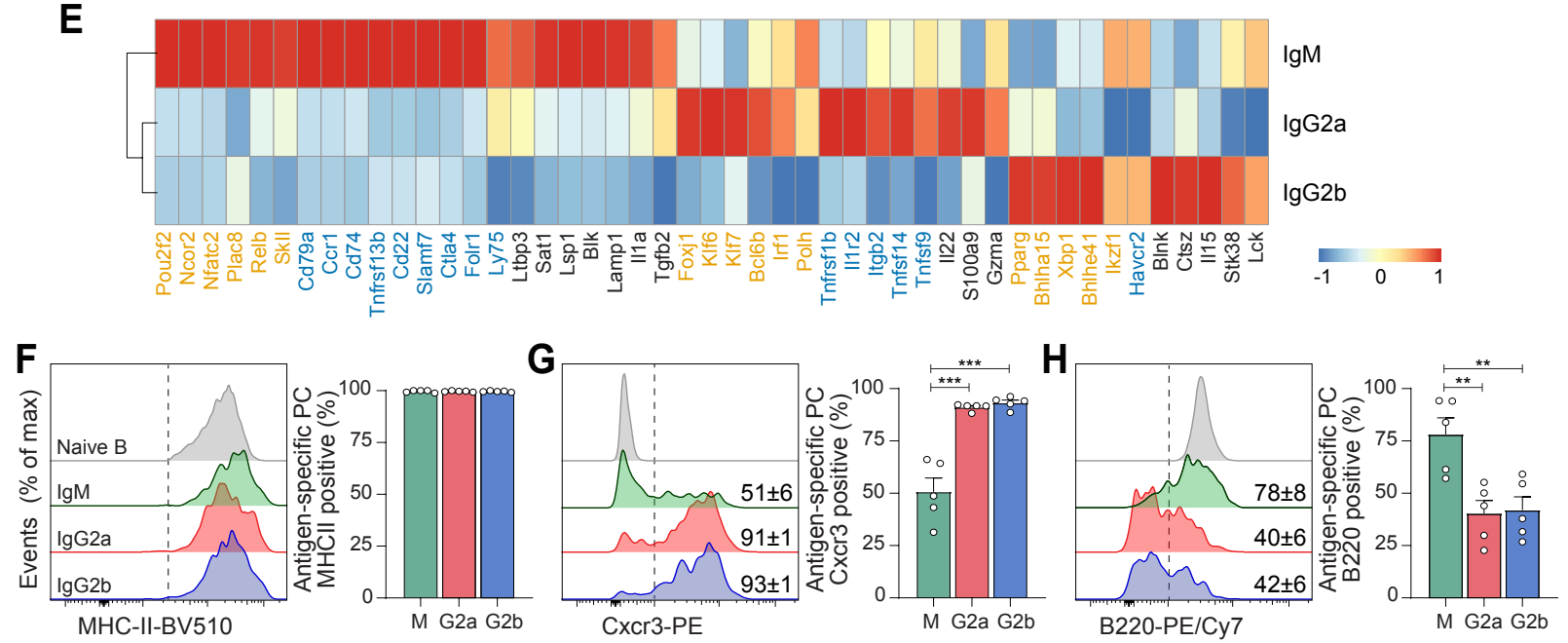
Figure 3: Inflammatory subclass IgG effector PC programs. (A) Flow cytometry of index

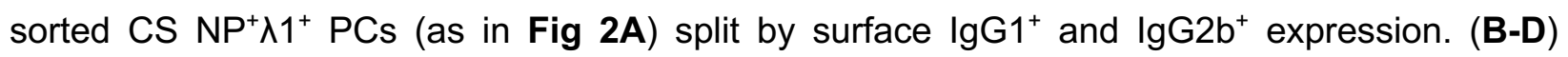
Differences in gene expression plotted by statistical significance and presented as volcano plots comparing d5 antigen-specific $\operatorname{lgM}^{+}$, $\lg \mathrm{g}_{2} \mathrm{a}^{+}$, and $\operatorname{lgG} 2 \mathrm{~b}^{+}$PCs. (E) Pseudobulk heatmap representation of differentially expressed genes from B-D. The color scale is based on z-score distribution. (F-H) Surface protein expression of MHC-II, Cxcr3 and B220 from antigen-specific PCs split by class compared to naive B cells $\left(\mathrm{CD}^{1} 9^{+} \lg \mathrm{D}^{+} \operatorname{IgM}^{+} \lambda 1^{-} \mathrm{CD} 138^{-} \mathrm{NP} \mathrm{P}^{-} \mathrm{G}^{-} \mathrm{CD} 3 \mathrm{e}^{-}\right)$. Numbers indicate the percentage of cells expressing each surface marker (mean \pm s.e.m., $n=5 ;{ }^{* *} p<0.01$, ${ }^{* * *} \mathrm{p}<0.001,2$ tailed unpaired Students $t$-test). For index sorted cells, $\mathrm{n}=109 \lg \mathrm{M}^{+}, 185 \lg \lg ^{+}$, 84 lgG2a ${ }^{+}$PCs. For B-E, genes labeled in orange represent transcriptional modifiers translocating to or residing in the nucleus, genes labeled in teal represent surface/membrane genes and genes in black represent cytosolic and secreted genes. 
bioRxiv preprint doi: https://doi.org/10.1101/2021.08.31.458458; this version posted September 1, 2021. The copyright holder for this preprint (which was not certified by peer review) is the author/funder. All rights reserved. No reuse allowed without permission.

\section{Figure 4}

A

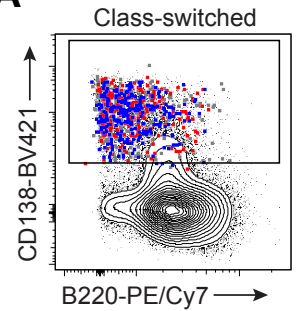

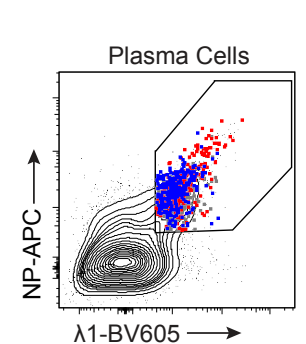

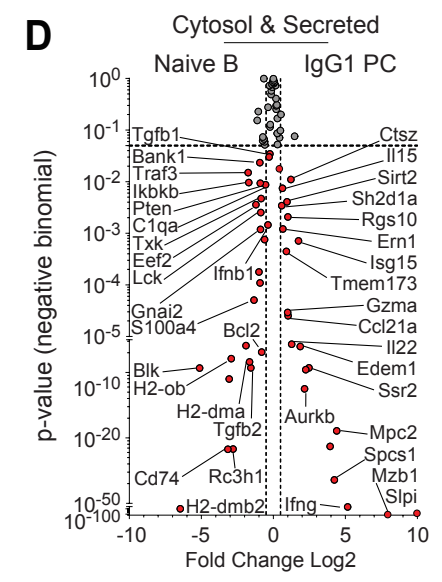

C
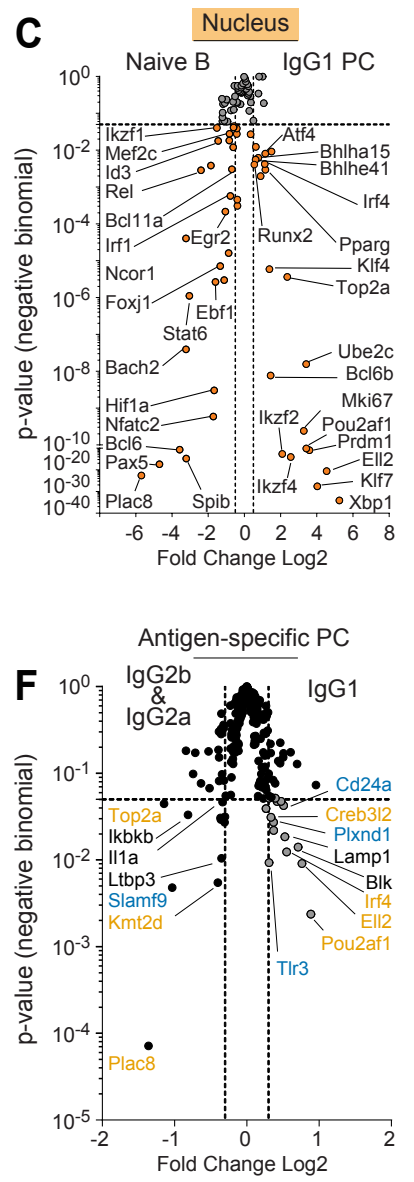

Day 14 NP-specific

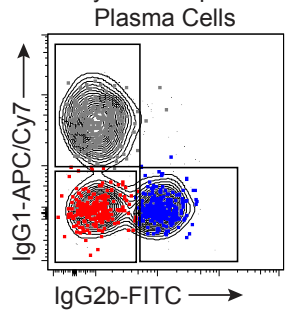

$\lg \mathrm{G} 2 \mathrm{~b}-\mathrm{FITC} \longrightarrow$

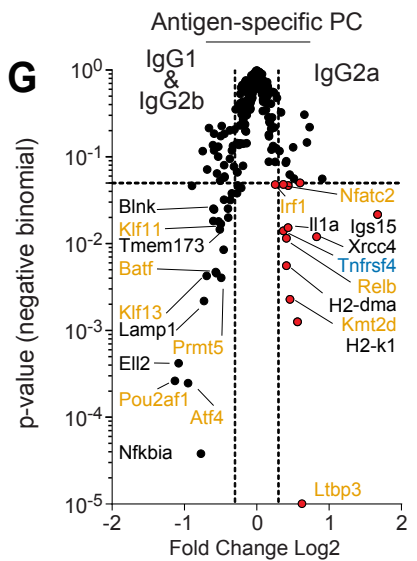

\section{E}

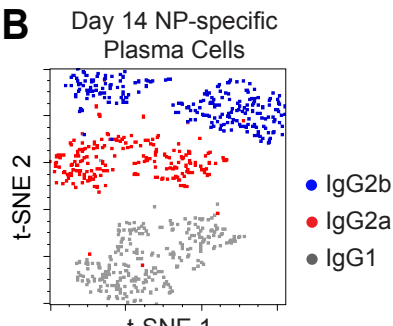

t-SNE 1
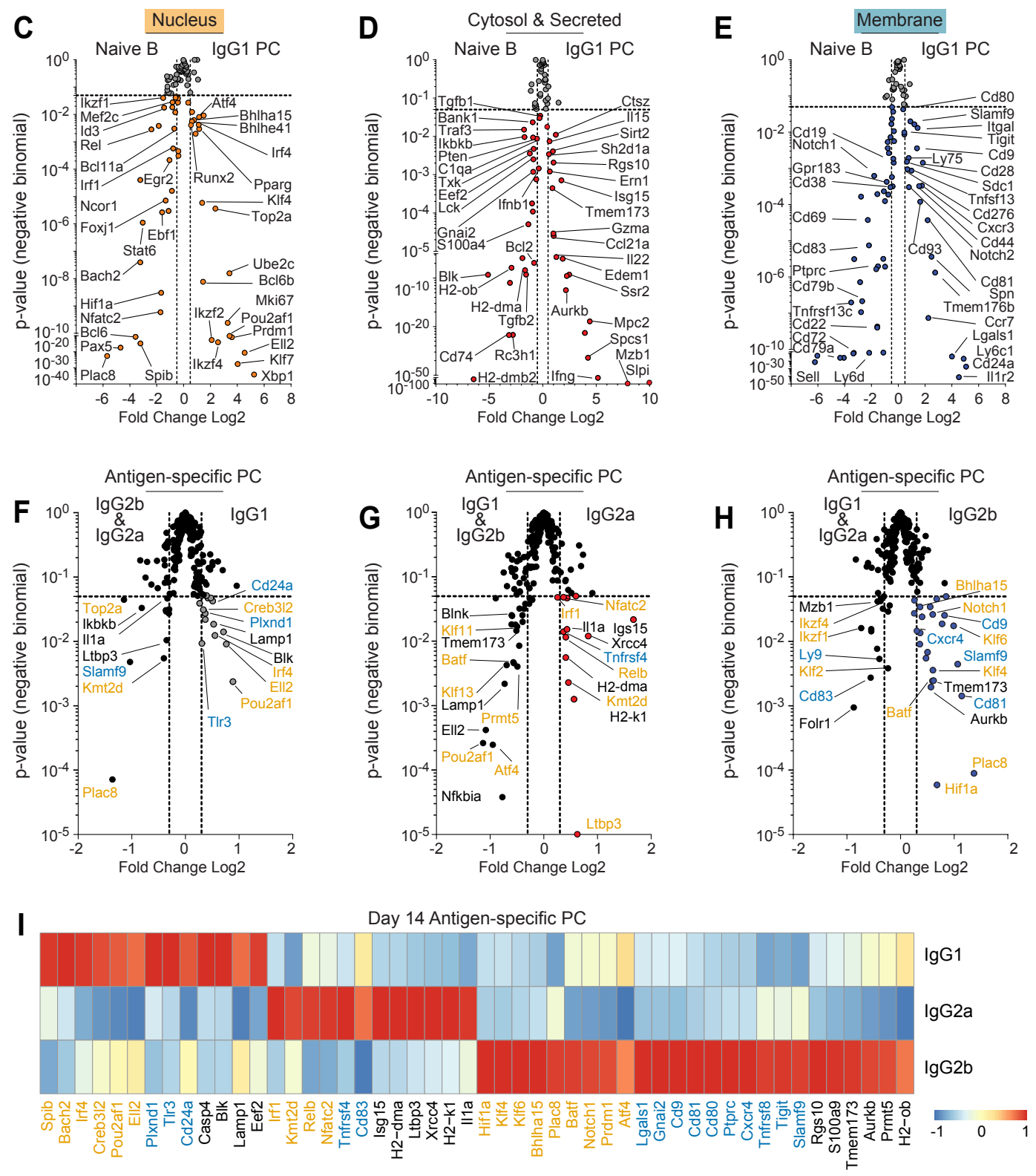
Figure 4: Divergent isotype-specific post-GC PC programs. (A) Index sorted antigen specific $\lg G 1^{+}, \lg G 2 b^{+}$, and $\lg G 2 a^{+} P C s$ overlaid on contour plots of total populations. (B) Dimensional reduction based on surface phenotype of index sorted PCs using tSNE (t-distributed stochastic neighbor embedding) ( $\left.n=290 \operatorname{lgG} 1^{+}, n=292 \operatorname{lgG} 2 b^{+}, n=228 \operatorname{lgG} 2 a^{+} P C s\right)$. (C-E) Differences in gene expression plotted by statistical significance and presented as volcano plots comparing

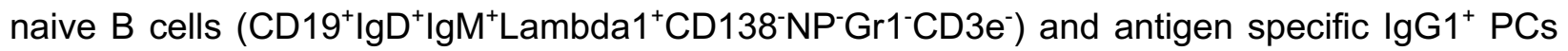
separated by gene categorization. (F-H) Differences in gene expression plotted by statistical significance and presented as volcano plots comparing antigen specific $\lg G 1^{+}(\mathbf{D}), \lg \lg ^{+}(\mathrm{E})$, and $\lg \mathrm{Ca}^{+}$(F) PCs compared to all other post-GC PCs. (I) Pseudobulk heatmap representation of differentially expressed genes from F-H using average gene expression values. The color scale is based on z-score distribution. ( $n=78$ naïve, $n=290 \operatorname{lgG} 1^{+}, n=292 \lg G 2 b^{+}, n=228 \lg G 2 a^{+} P C s$ ). For $\mathbf{F}-\mathbf{H}$, genes labeled in orange represent transcriptional modifiers translocating to or residing in the nucleus, genes labeled in teal represent surface/membrane genes and genes in black represent cytosolic and secreted genes. 
bioRxiv preprint doi: https://doi.org/10.1101/2021.08.31.458458; this version posted September 1, 2021. The copyright holder for this preprint (which was not certified by peer review) is the author/funder. All rights reserved. No reuse allowed without permission.

Figure 5

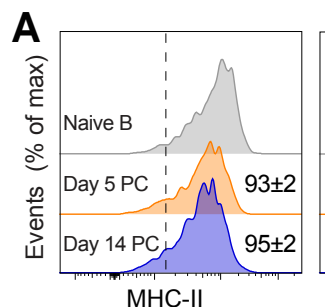

$\mathrm{MHC}-\mathrm{II}$

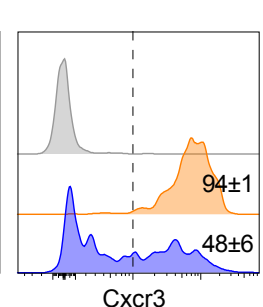

Cxcr3

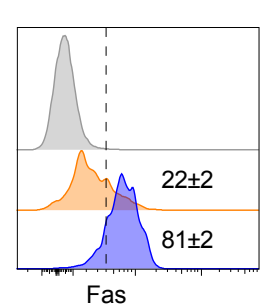

Fas
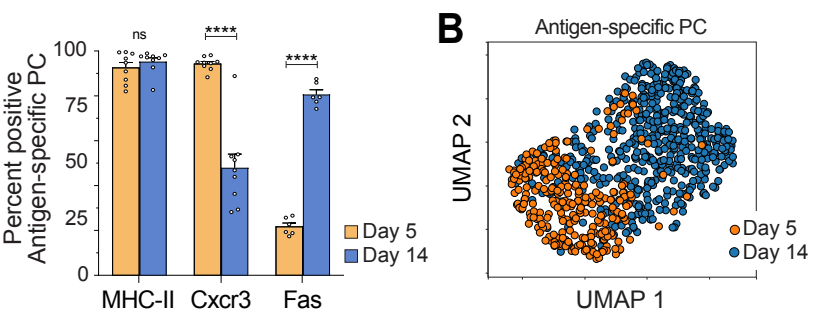

E

D
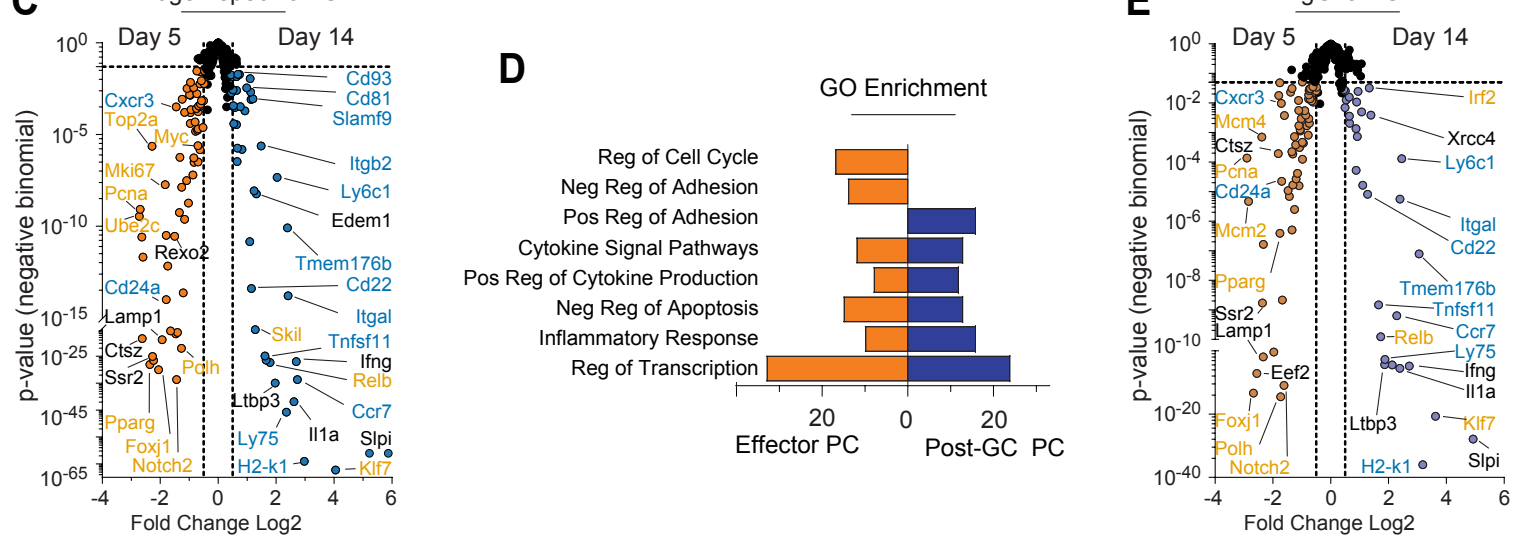

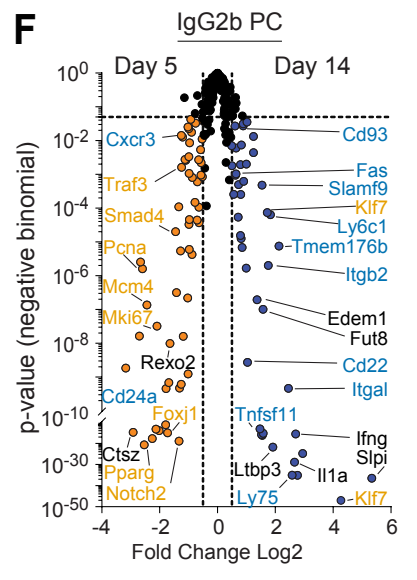

G Up in Day 5 Antigen-specific PC

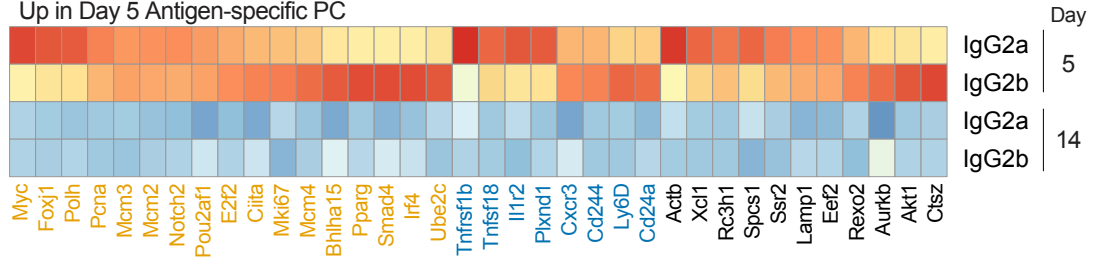

Up in Day 14 Antigen-specific PC

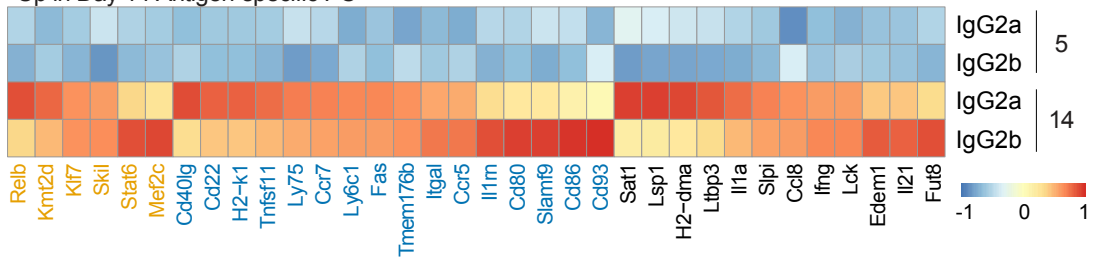


Figure 5: Separable inflammatory post-GC PC programs. (A) Surface protein expression of MHC-II, Cxcr3 and Fas in antigen specific d5 and d14 PCs compared to naive B cells. Numbers indicate percentage of cells expressing each marker. (mean \pm s.e.m., $n=6-9$ mice, ${ }^{* * *} p<0.0001$, ns, not significant; 2 tailed unpaired Students $t$-test). (B) UMAP reduction of antigen specific d5 and d14 PCs using gene expression ( $n=291$ d5 PCs, n=520 d14 PCs). (C) Differences in gene expression plotted by statistical significance and presented as a volcano plot comparing d5 and d14 antigen specific PCs (IgG2a $a^{+}$and $\operatorname{lgG} 2 b^{+}$only). (D) The number of genes upregulated aligning to the indicated GO pathway showing d5 PCs in orange and d14 PCs in blue. (Cell cycle, GO:0051726; Neg Adhesion, GO:0007162; Pos Adhesion, GO:0022409; Cytokine Sig Pathway, GO 0019221; Pos Cytokine Production, GO:0001819; Neg Apoptosis, GO:0043066; Inflammatory resp, GO:0006954; Transcription, GO:0006355) (E, F) Differences in gene expression plotted by statistical significance and presented as a volcano plot comparing d5 and d14 antigen specific PCs split by $\operatorname{lgG} 2 b^{+}(\mathbf{E})$ or $\lg { }^{2} a^{+}(\mathbf{F})$. (G) Pseudobulk heatmap representation of differentially expressed genes between d5 and d14 PCs split by subclass. The color scale is based on z-score distribution. Genes labeled in orange represent transcriptional modifiers translocating to or residing in the nucleus, genes labeled in teal represent surface/membrane genes and genes in black represent cytosolic and secreted genes. 


\section{Figure 6}
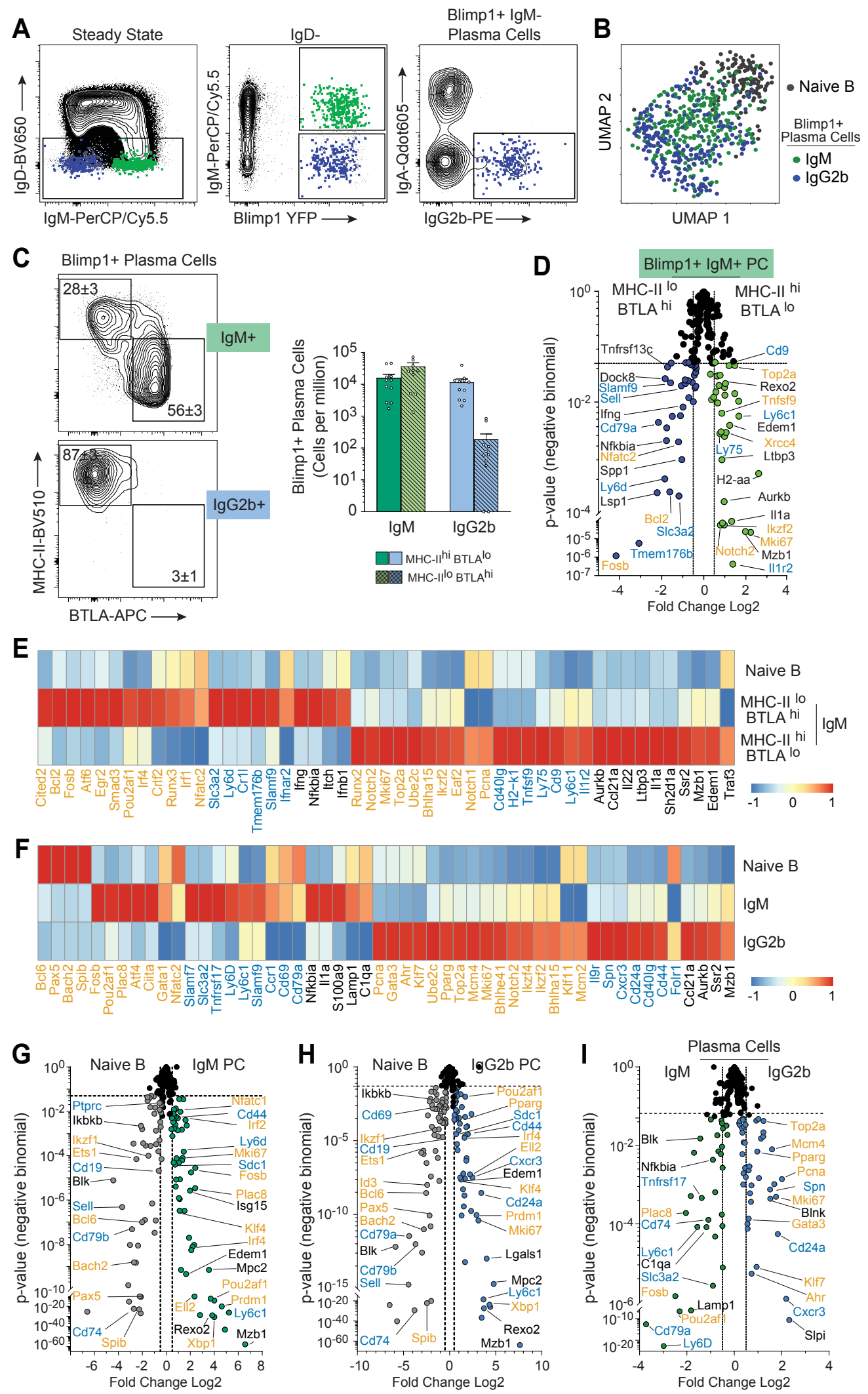
Figure 6: Divergent IgM and IgG2b PC programs in the steady state. (A) FACS index sorted $\operatorname{lgM}^{+}$and $\operatorname{lgG}^{+}$PCs taken from SP of an unimmunized Blimp-YFP mouse. (B) Dimensional reduction on index sorted PCs from $(\mathbf{A})$ based on gene expression distribution using uniform manifold approximation and projection (UMAP). $n=303 \lg \mathrm{M}^{+}, 220 \lg \mathrm{I}^{+} \mathrm{b}^{+}, 150$ naive $\mathrm{B}$ cells. (C) Expression of surface MHC-II and BTLA by $\operatorname{lgM}^{+}$and $\operatorname{lgG} 2 \mathrm{~b}^{+} \mathrm{PC}$ compartments. Numbers indicate positive percentage expressing. At right, quantification in cells per million of each PC isotype by phenotypic subpopulations (mean \pm s.e.m., $n=11$ ). (D) Differences in gene expression plotted by statistical significance and presented as a volcano plot comparing MHC-II ${ }^{\text {hi }} B$ TLA ${ }^{\text {lo }}$ $(n=141)$ and $M H C-$ II $^{\text {lo BTLA }}{ }^{\text {hi }}(n=92) \operatorname{lgM}^{+}$PCs. (E) Pseudobulk heatmap representation of differentially expressed genes generated in $\mathbf{D}$ compared to naïve B cells, or (F) differentially expressed genes between naïve B cells and class specific PCs as shown in volcano plot representations of differentially expressed genes between naïve B cells and $(\mathbf{G}) \operatorname{lgM}^{+},(\mathbf{H}) \lg \lg ^{+}$ or (I) $\operatorname{lgM}^{+}$versus IgG2b+ PCs. For pseudobulk heatmaps, the color scale is based on z-score distribution. Genes labeled in orange represent transcriptional modifiers translocating to or residing in the nucleus, genes labeled in teal represent surface/membrane genes and genes in black represent cytosolic and secreted genes. 
bioRxiv preprint doi: https://doi.org/10.1101/2021.08.31.458458; this version posted September 1, 2021. The copyright holder for this preprint (which was not certified by peer review) is the author/funder. All rights reserved. No reuse allowed without permission.

\section{Figure 7}

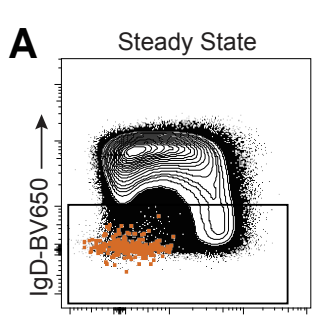

IgM-PerCP/Cy5.5

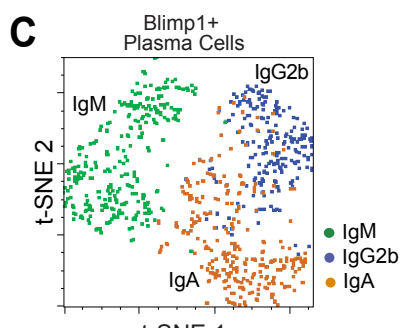

t-SNE 1
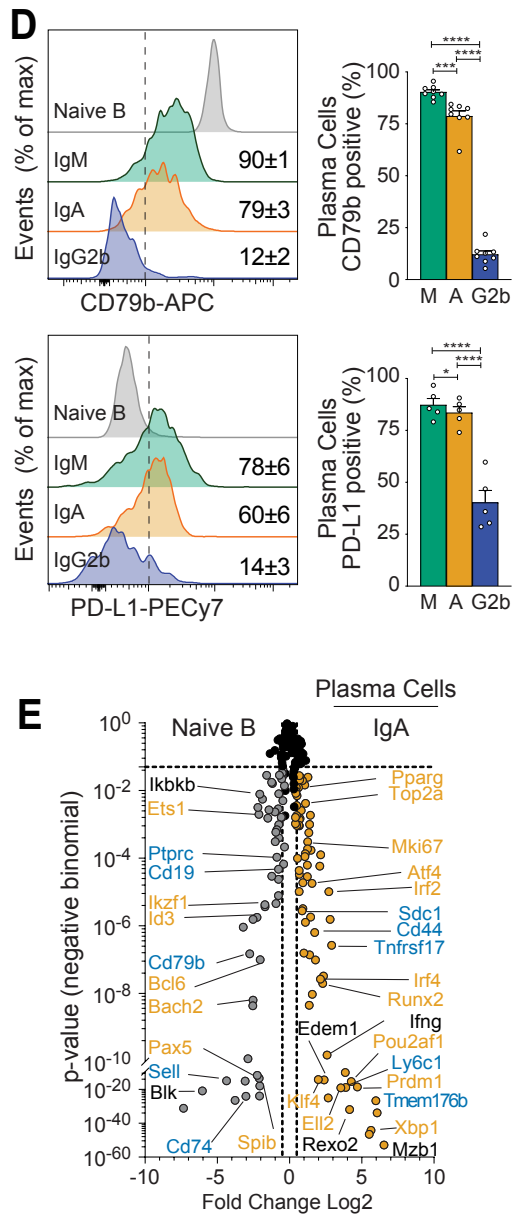

IgD-

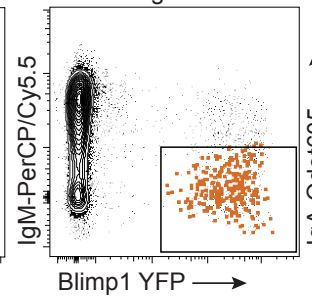

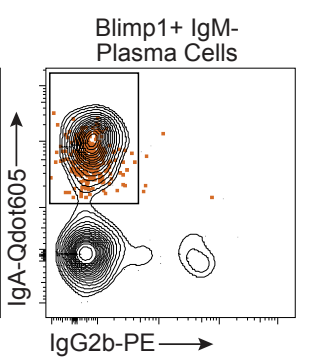

B

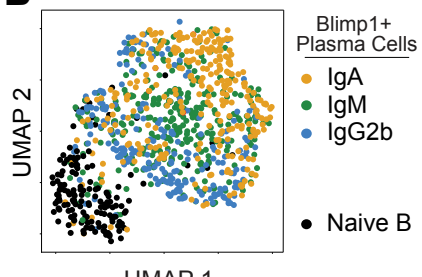

UMAP 1

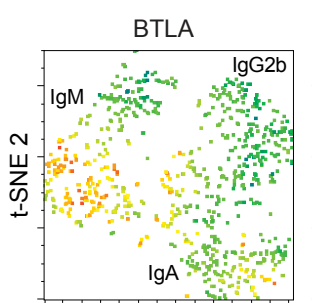

t-SNE 1
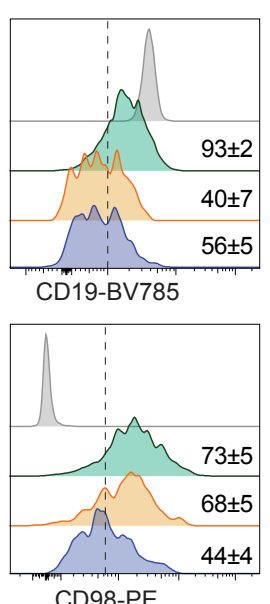

CD98-PE

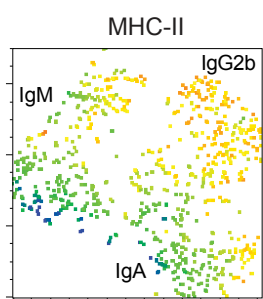

$\lg \mathrm{A}=$

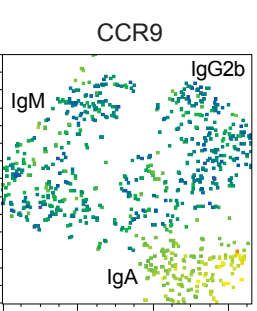

Min Max
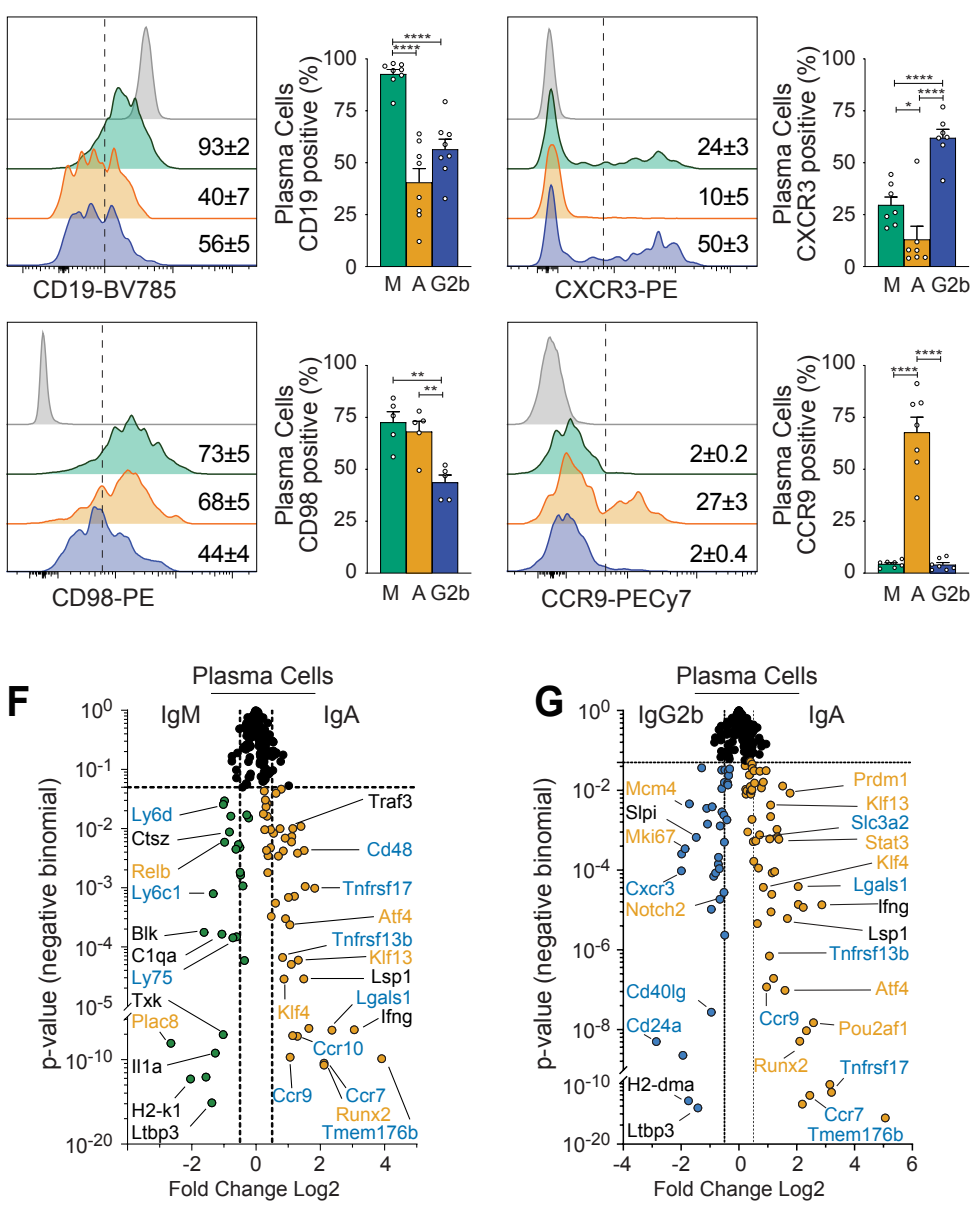

\section{H}

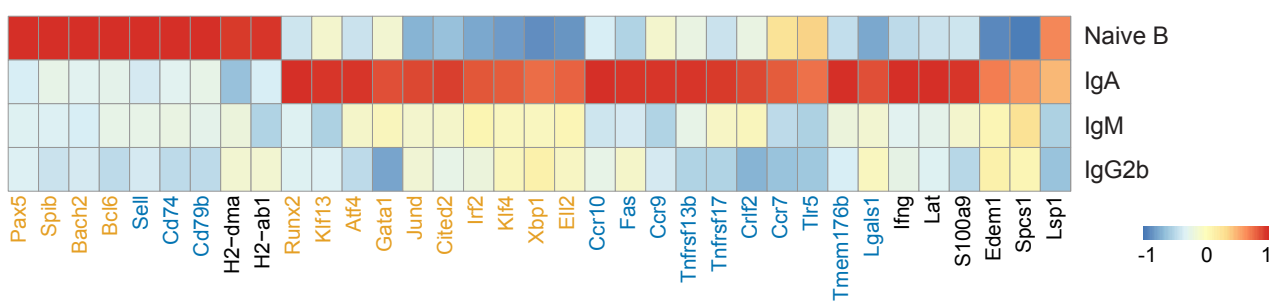


Figure 7: Distinct IgA PC programming for mucosal immunity. (A) FACS index sorted splenic-derived $\lg \mathrm{A}^{+} \mathrm{PCs}(\mathrm{n}=276)$ taken from spleen $(\mathrm{SP})$ of an unimmunized Blimp-YFP mouse. (B) tSNE (t-distributed stochastic neighbor embedding) dimensional reduction on index sorted $\lg \mathrm{M}^{+}, \lg \mathrm{A}^{+}$and $\lg G 2 \mathrm{~b}^{+} \mathrm{PCs}$ based on phenotype with overlay of expression level for selected proteins. (C-D) Expression of surface protein markers from Blimp-YFP ${ }^{+}$class specific PCs compared to naïve B cells. Percentage of cells expressing is indicated on plots with quantification at right of percentage expressing (mean \pm s.e.m., $n=6 ; 2$ tailed unpaired Students $t$-test, ${ }^{*} p<$ $\left.0.05,{ }^{* *} p<0.01,{ }^{* * *} p<0.001,{ }^{* * *} p<0.0001\right)$. (E) Differences in gene expression plotted by statistical significance and presented as volcano plots comparing naïve $B$ cells and $\lg A^{+} P C,(F)$ $\lg \mathrm{M}^{+}$versus $\lg \mathrm{A}^{+} \mathrm{PC}$ and $(\mathbf{G}) \lg G 2 \mathrm{~b}^{+}$versus $\lg \mathrm{A}^{+} \mathrm{PC}$. (H) Pseudobulk heatmap representation of differentially expressed genes focused on $\lg \mathrm{A}^{+} \mathrm{PCs}$. The color scale is based on z-score distribution. In E-G, genes labeled in orange represent transcriptional modifiers translocating to or residing in the nucleus, genes labeled in teal represent surface/membrane genes and genes in black represent cytosolic and secreted genes. For A, B, E-G: $n=303 \operatorname{lgM}^{+}, 220 \lg 2^{+} b^{+}, 276$ $\lg A^{+}$PCs, 150 Naïve $B$. 
bioRxiv preprint doi: https://doi.org/10.1101/2021.08.31.458458; this version posted September 1, 2021. The copyright holder for this preprint (which was not certified by peer review) is the author/funder. All rights reserved. No reuse allowed without permission.
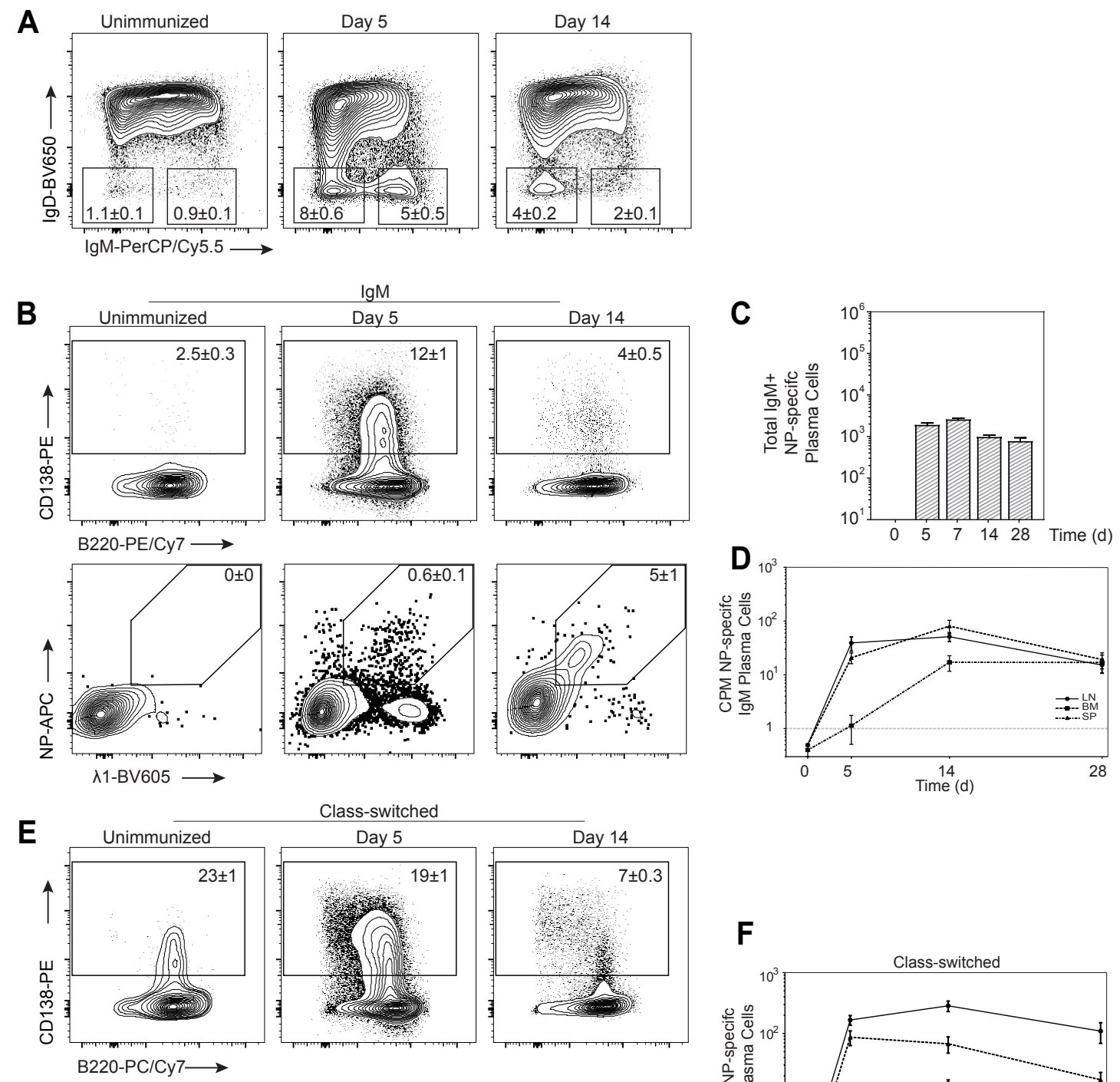

Class-switched
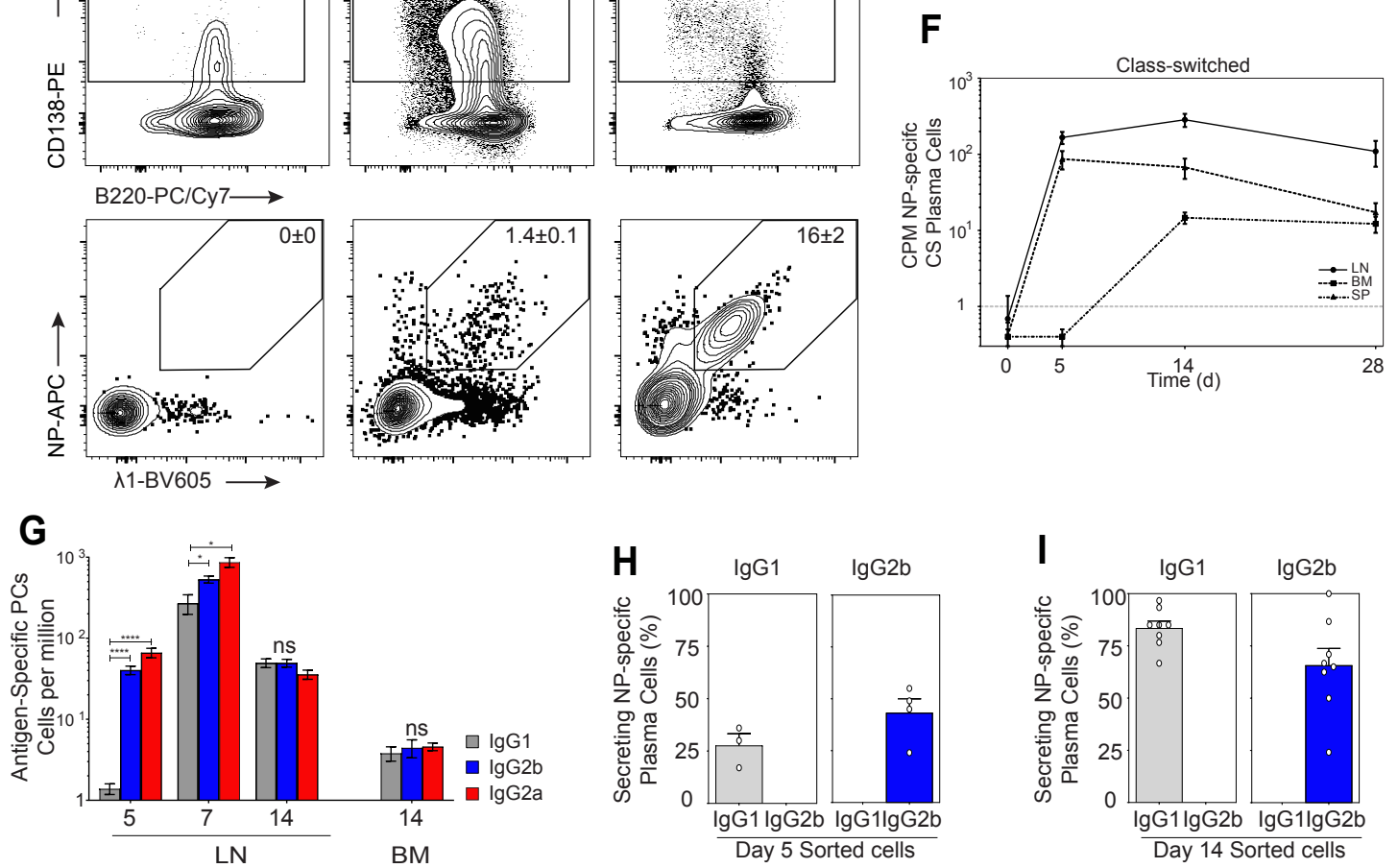

Supplementary Fig 1: Spatiotemporal access to class specific Plasma Cells. (A) Flow cytometry from draining lymph nodes before (unimmunized), and 5 or 14 days after primary immunization with NP-KLH in MPL adjuvant gated as Gr1-CD3- CD19+ and/or CD138+ B cells. Numbers in outlined areas indicate percent of cells (mean \pm s.e.m.) (B) Gating strategy of IgM PCs to isolate $N P+L a m b d a 1+P C s$ with (C) quantification and (D) distribution over time in the dLN (LN), spleen (SP) and bone marrow (BM). (E, F) Gating strategry of Class Switch PCs and temporal quantification of NP+Lambda1+ PCs across dLN, SP and BM at time points indicated after immunization. (G) Quantification of isotype specific NP+Lambda1+ PCs at time points indicated after immunization in the dLN and BM ${ }^{*} p<0.05,{ }^{* * *} p<0.0001 ; 2$ tailed unpaired Students $t$ test). Single cell sorted antigen specific Elispot at day 5 (H) and d14 (I) for IgG2b+ (red) and IgG1+ PCs (grey) from the dLN. Frequency is shown after exposure to either anti-lgG2b+ secondary antibody (left column) or anti-lgG1+ secondary antibody (right column). Data are representative of at least two experiments (except day 7 in (C) 1 experiment); mean \pm s.e.m. of $n=3-12$ mice. 
bioRxiv preprint doi: https://doi.org/10.1101/2021.08.31.458458; this version posted September 1, 2021. The copyright holder for this preprint (which was not certified by peer review) is the author/funder. All rights reserved. No reuse allowed without permission.

A
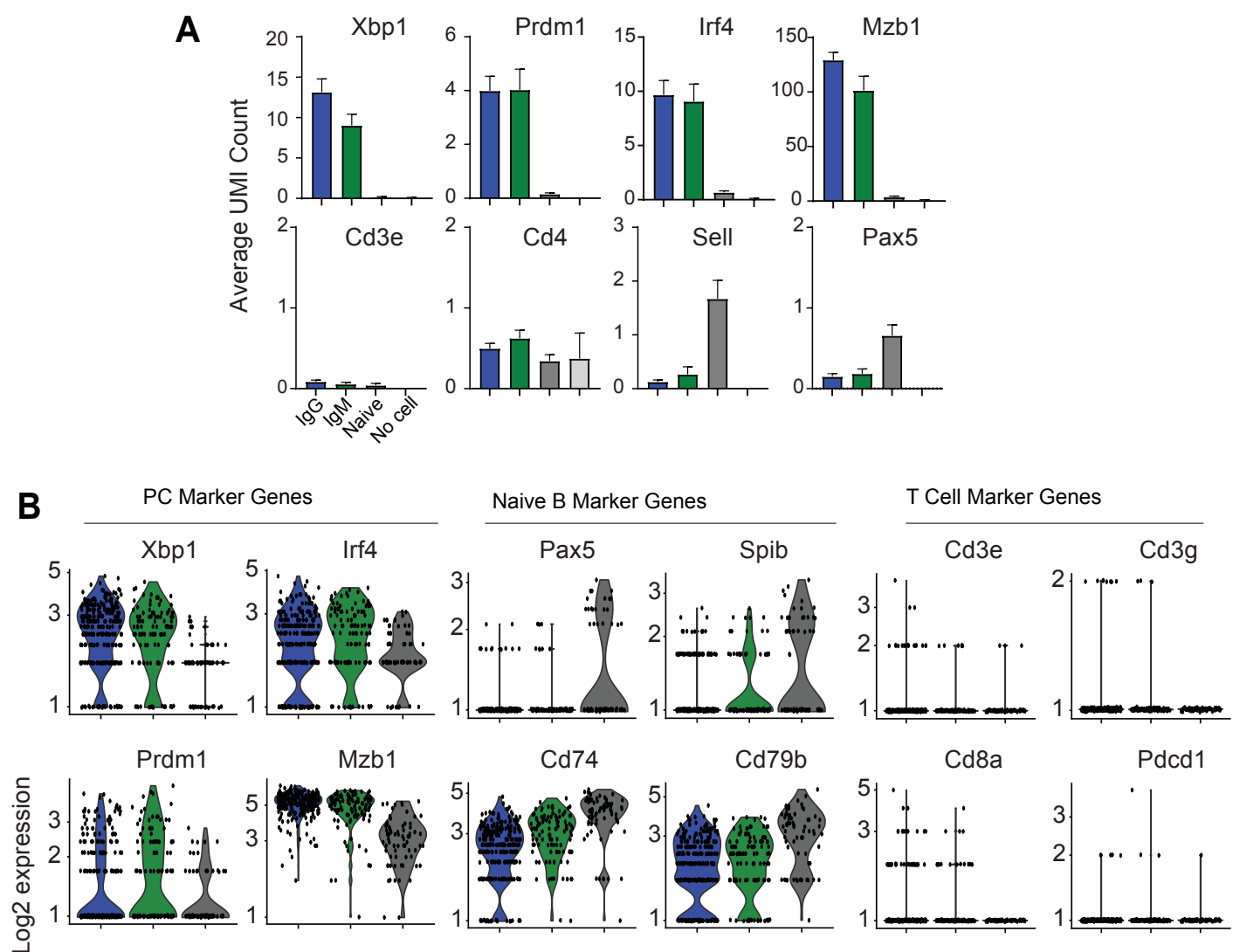

$\mathrm{Cd} 79 \mathrm{~b}$

Cd8a

Pdcd1

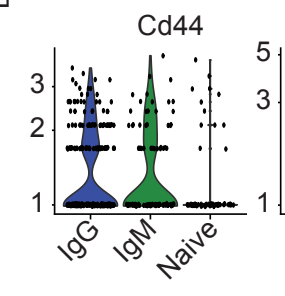

Ly6c1
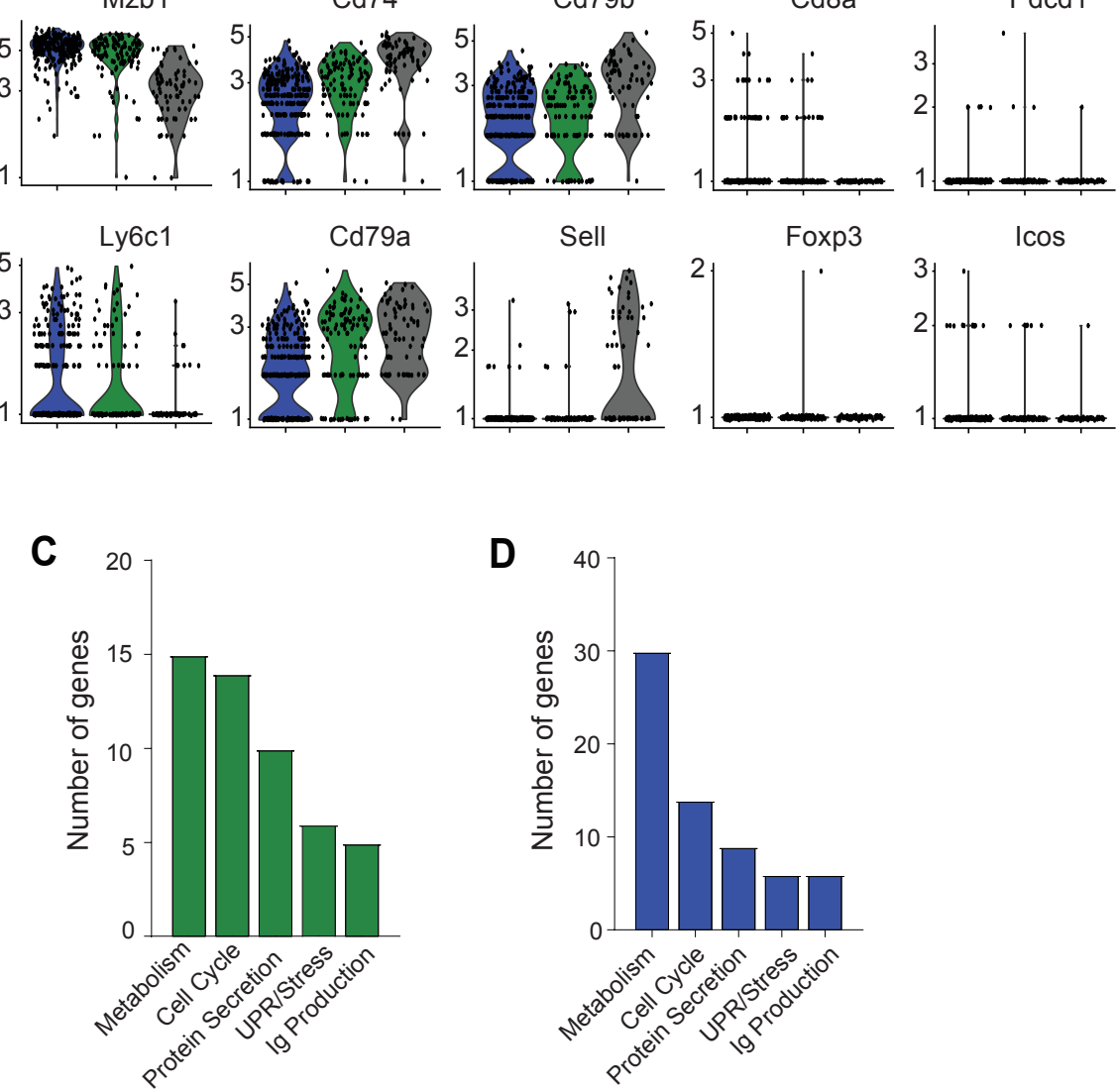

Supplementary Fig 2: Gene targeted single cell RNA sequencing using qtSEQ. (A) Average expression of raw UMI counts for selected genes taken from IgG, IgM, Naive B single cells compared to control empty well samples. $n=109$ lgM+, $n=269$ IgG,$+ n=73$ naive $B$ cells, $n=16$ no cell control wells. (B) Normalized and scaled UMl counts plotted using a Log2 scale for PC, Naive B and T cell lineage marker genes for lgG+, IgM+ and naive B cells used in Figure 2. (C) Go enrichment of the genes upregulated in IgM+ PCs over naive B cells or (D) lgG+ over naïve B cells. (Protein Metabolism, GO:0051246; Cell Cycle, GO:0051726; Protein Secretion, GO:1903530; UPR/Stress, GO:0006986; Immunoglobulin Production, GO:0002639). 

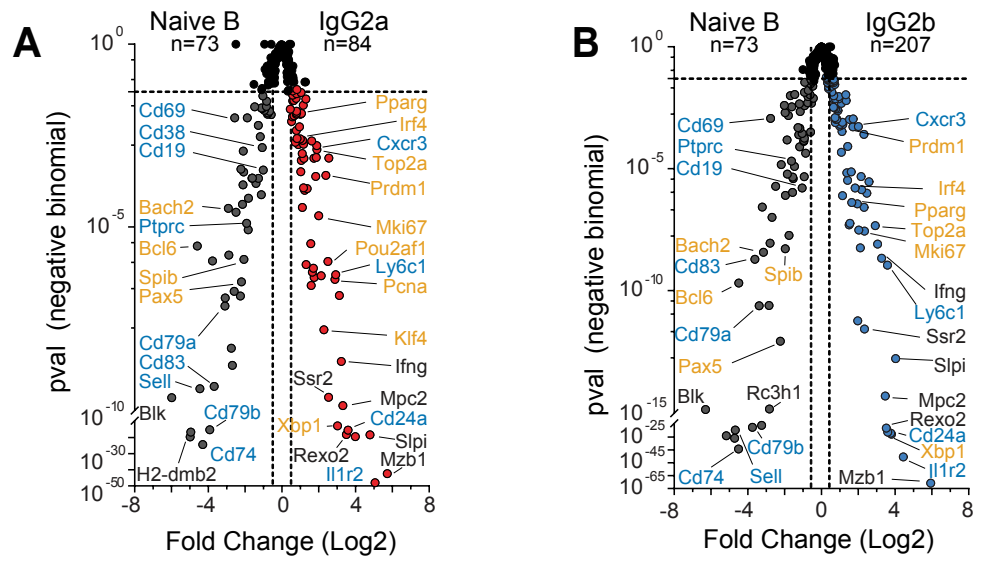

Supplementary Fig 3: Distinct programming of inflammatory subclass IgG effector PCs compared to naïve $B$ cells. (A) Differences in gene expression plotted by statistical significance and presented as volcano plots comparing naïve $B$ cells and day 5 antigen specific $\lg G 2 a+$ or (B) $\lg G 2 b+P C$. For index sorted cells $n=207$ lgG2b+, n=84 lgG2a+ PCs, n=73 naïve B cells. Genes labeled in orange represent transcriptional modifiers translocating to or residing in the nucleus, genes labeled in teal represent surface/membrane genes and genes in black represent cytosolic and secreted genes. 
bioRxiv preprint doi: https://doi.org/10.1101/2021.08.31.458458; this version posted September 1, 2021. The copyright holder for this preprint (which was not certified by peer review) is the author/funder. All rights reserved. No reuse allowed without permission.

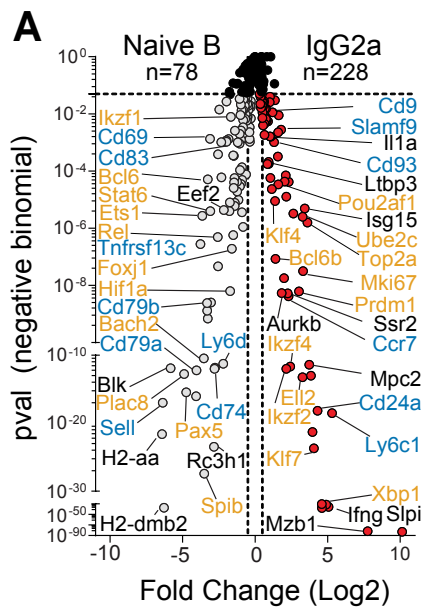

C

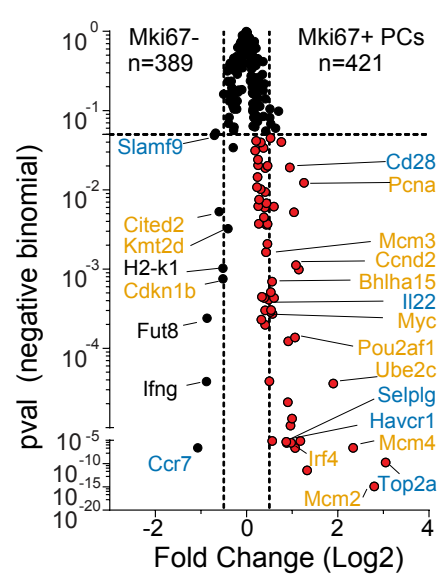

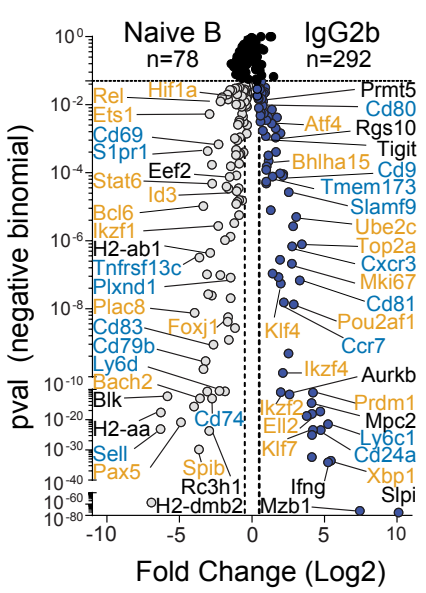
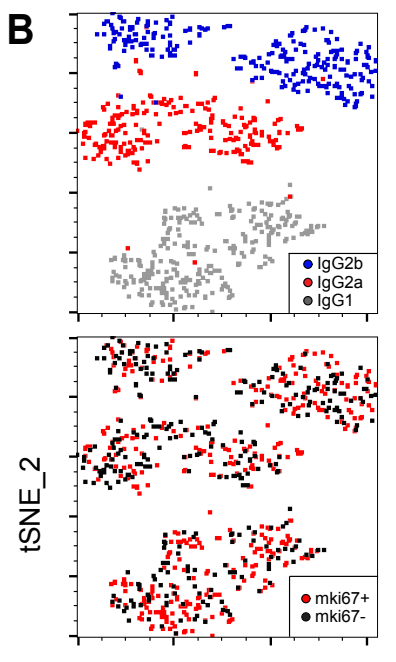

tSNE_1

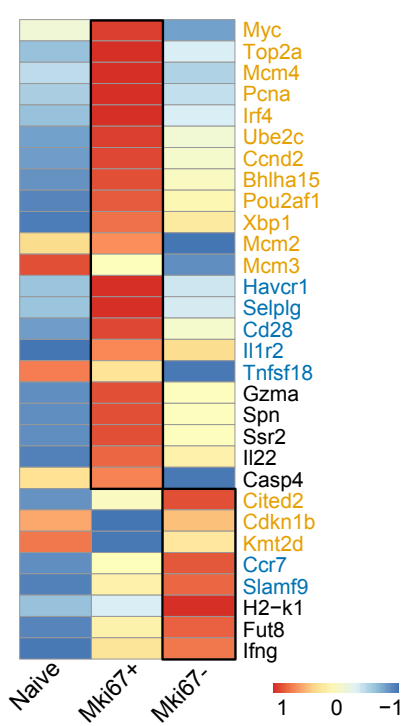

D

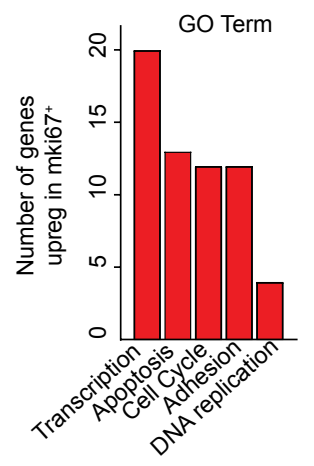

Supplementary Fig 4: Time from GC cycling impacts post-GC PC transcriptional programming. (A) Differences in gene expression plotted by statistical significance and presented as volcano plots comparing naive B cells $(C D 19+\operatorname{lgD}+\operatorname{lgM}+$ Lambda1+CD138-NP-Gr1-CD3e-) and antigen specific IgG2a+ or IgG2b+ PCs. (B) Dimensional reduction based on surface phenotype of index sorted PCs using tSNE (t-distributed stochastic neighbor embedding) with positive expression of Mki67 overlaid on cells in red. ( $n=290 \operatorname{lgG} 1+, n=292 \lg 2 \mathrm{~b}+, n=228 \lg \mathrm{g} 2 a+P C s)$. (C) Differences in gene expression plotted by statistical significance and presented as a volcano plot comparing Mki67+ and Mki67- PCs with pseudobulk heatmap representation of differentially expressed genes. The color scale is based on z-score distribution. (D) Number of genes for each GO enrichment category of genes upregulated by Mki67+ PCs. (Transcription, GO:0045944; Apoptosis, G00043065; Cell Cycle, GO:0051726; Adhesion, GO:1903037; DNA replication, GO:0006261). 
bioRxiv preprint doi: https://doi.org/10.1101/2021.08.31.458458; this version posted September 1, 2021. The copyright holder for this preprint (which was not certified by peer review) is the author/funder. All rights reserved. No reuse allowed without permission.

A

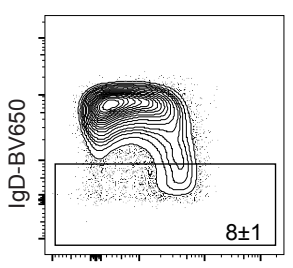

IgM-PerCP/Cy5.5

B

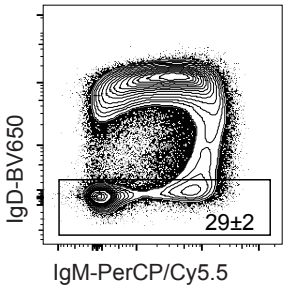

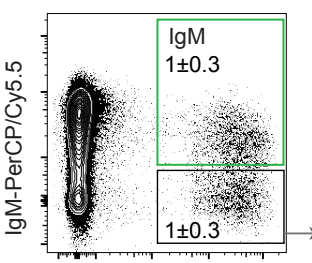

Blimp1YFP-FITC

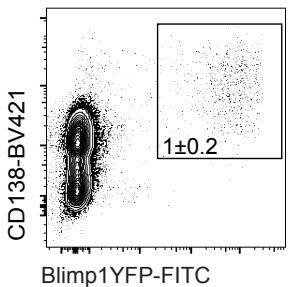

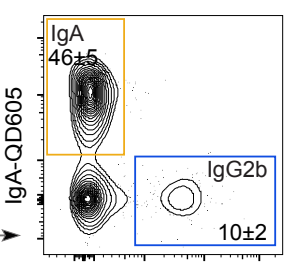

$\lg \mathrm{G} 2 \mathrm{~b}-\mathrm{PE}$

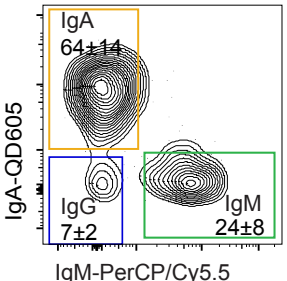

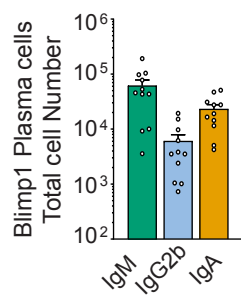

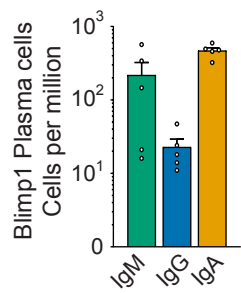

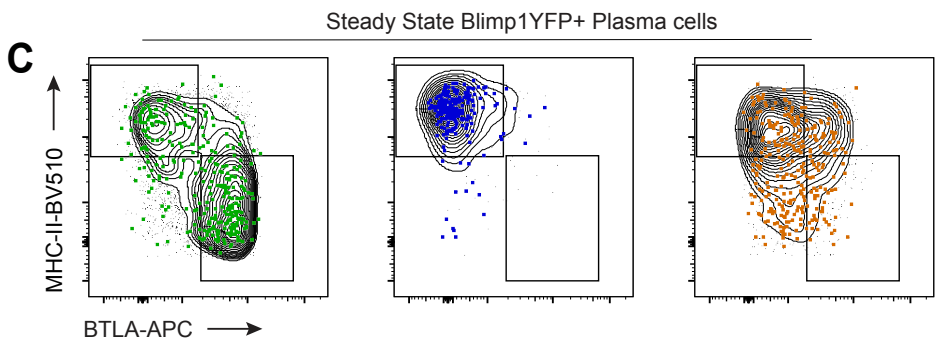
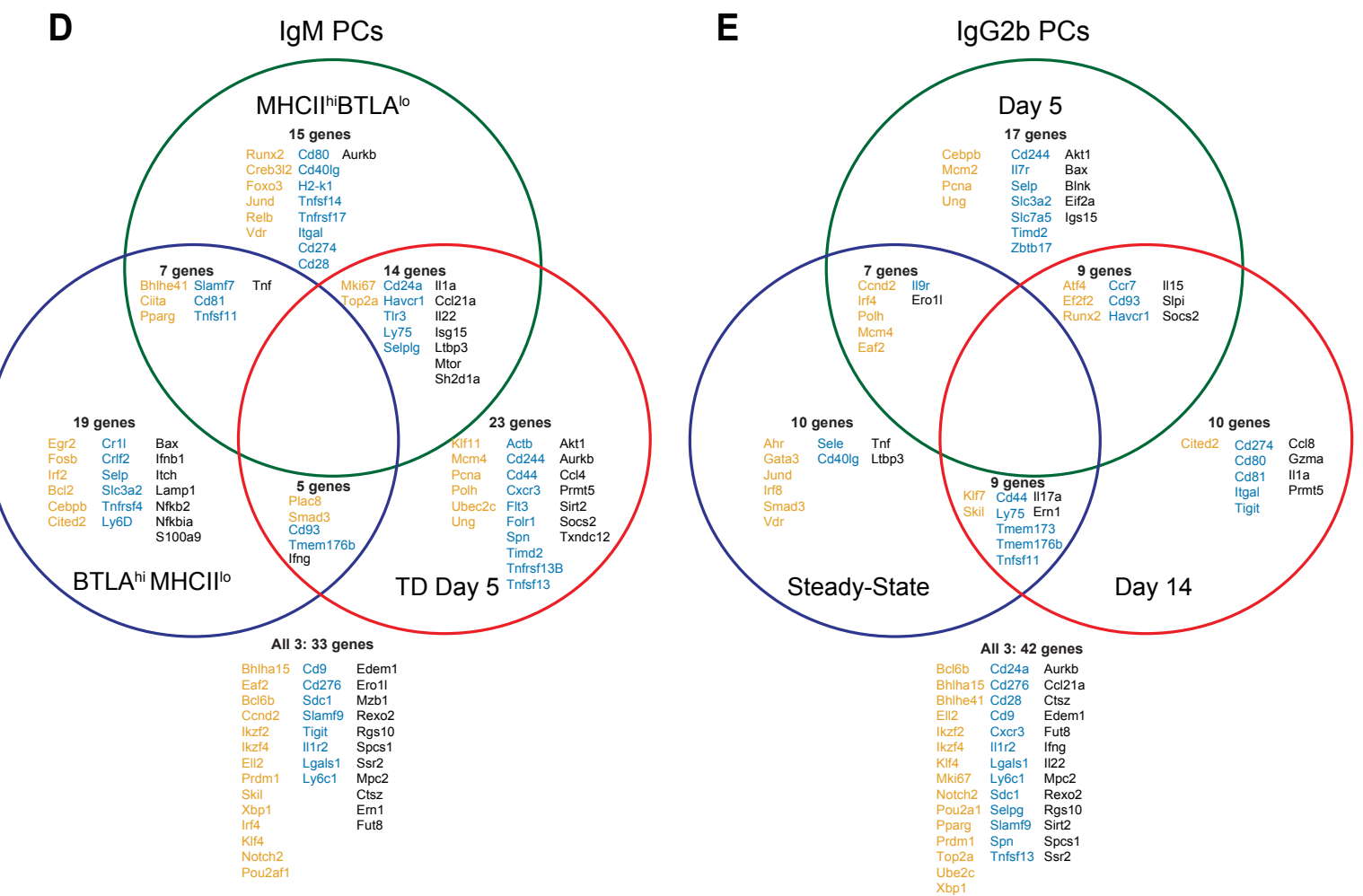

Supplementary Fig 5: Conservation of class-linked molecular programming of PCs. (A) Representative FACS gating strategy for isolation of $\operatorname{lgM}+, \lg 2 \mathrm{~b}+$, and $\lg \mathrm{A}+\mathrm{PC}$ taken from spleen (SP) of an unimmunized Blimp-YFP mouse. Quantification of total PCs by class at right (mean \pm s.e.m., $n=11$ ) (B) Representative FACS gating strategy for isolation of $\operatorname{lgM}+$, IgG+, and IgA+ PCs taken from $B M$ of an unimmunized Blimp-YFP mouse. (mean \pm s.e.m., $n=5$ ). Quantification of PCs by class in cells per million at right. (C) Index sorted PCs distributed by MHC and BTLA protein expression overlaid on bulk population gating. Venn diagram showing genes that are upregulated in each defined IgM+ PC (D) or IgG2b+ (E) PCs compared to naïve B cells. IgM PCs are divided into day 5 effector ( $n=109$ ), MHC-IIhiBTLAlo $(n=141)$ and MHC-IIloBTLAhi $(n=91)$. IgG2b+ PCs are divided into day $5(n=185)$, day $14(n=292)$ and steady state $(n=220)$ cells. Overlapping regions indicated shared upregulation of genes. Genes upregulated in all 3 populations are listed outside the venn diagram below. Genes labeled in orange represent transcriptional modifiers translocating to or residing in the nucleus, genes labeled in teal represent surface/membrane genes and genes in black represent cytosolic and secreted genes. 
bioRxiv preprint doi: https://doi.org/10.1101/2021.08.31.458458; this version posted September 1, 2021. The copyright holder for this preprint (which was not certified by peer review) is the author/funder. All rights reserved. No reuse allowed without permission.

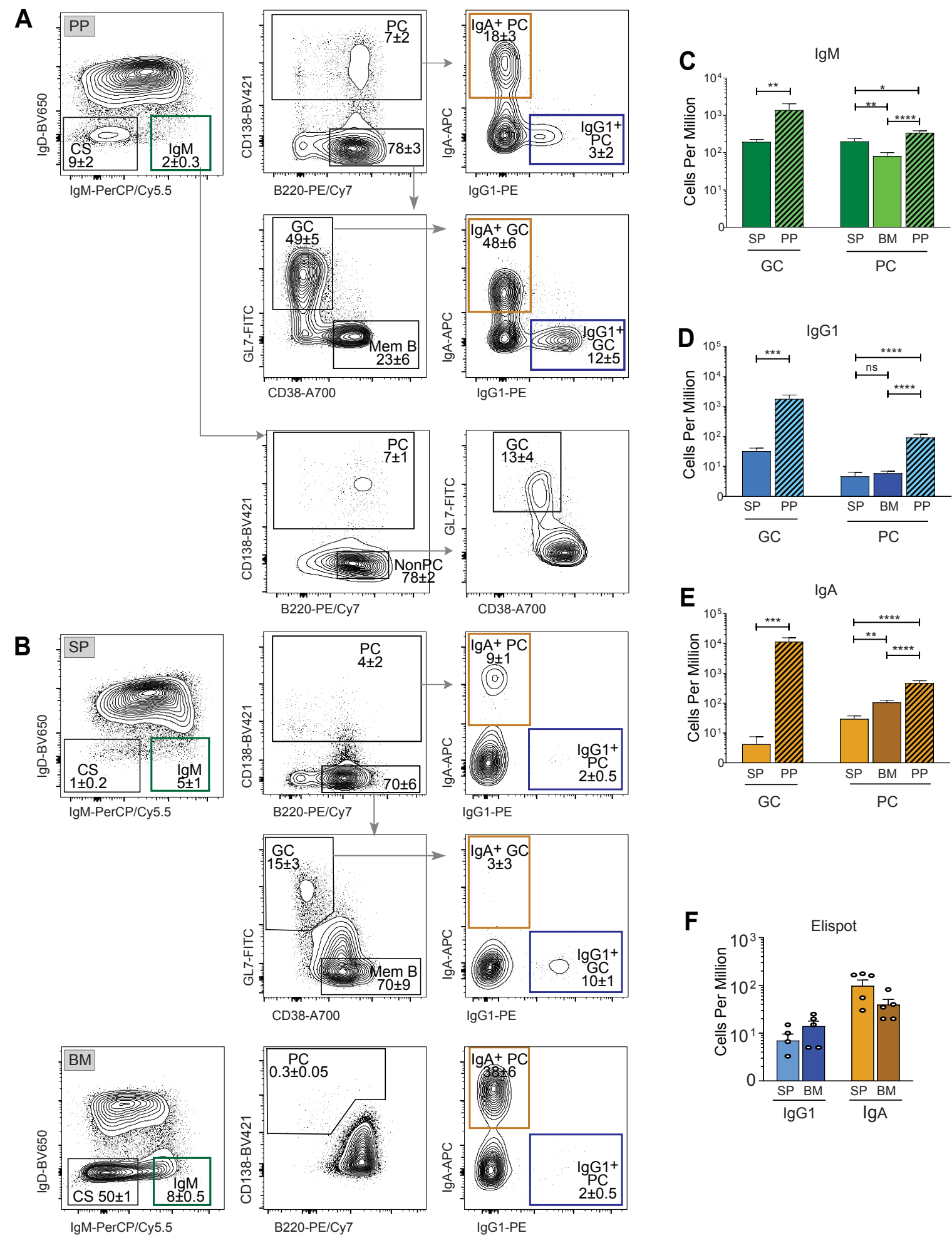

Supplementary Fig 6: The ongoing response in the steady state murine system presents organ and B cell class based heterogeneity. (A) Representative gating of B cells from the Peyer's Patches (PP) of an unimmunized C57/B6 mouse divided into class switched (CS, IgD-IgM-) or IgM+ populations. Plasma cells (PC, CD138+) and Germinal center (GC, CD138-GL7+CD38-) cells are shown divided by $\operatorname{lgM}+$, IgA+ and IgG1+ isotypes. (B) Representative gating of B cells from the spleen (SP, top) and bone marrow (BM, bottom) of an unimmunized C57/B6 mouse. Quantification of $\operatorname{lgM}+(\mathrm{C}), \lg \mathrm{g} 1+(\mathrm{D})$, and $\lg A+(\mathrm{E}) \mathrm{B}$ cells from the SP, PP, BM as gated in a-c. (For PP $n=6, S P n=14, B M n=15$; mean \pm s.e.m., two tailed unpaired t test; ${ }^{*} p<0.05$, ${ }^{* *} p<0.01,{ }^{* * *} p<0.001$, $\left.{ }^{* * *} p<0.0001\right)$. (F) Elispot frequency in cells per million of PCs from the SP and BM ( $n=5$ mean \pm s.e.m.). 
bioRxiv preprint doi: https://doi.org/10.1101/2021.08.31.458458; this version posted September 1, 2021. The copyright holder for this preprint (which was not certified by peer review) is the author/funder. All rights reserved. No reuse allowed without permission.

A
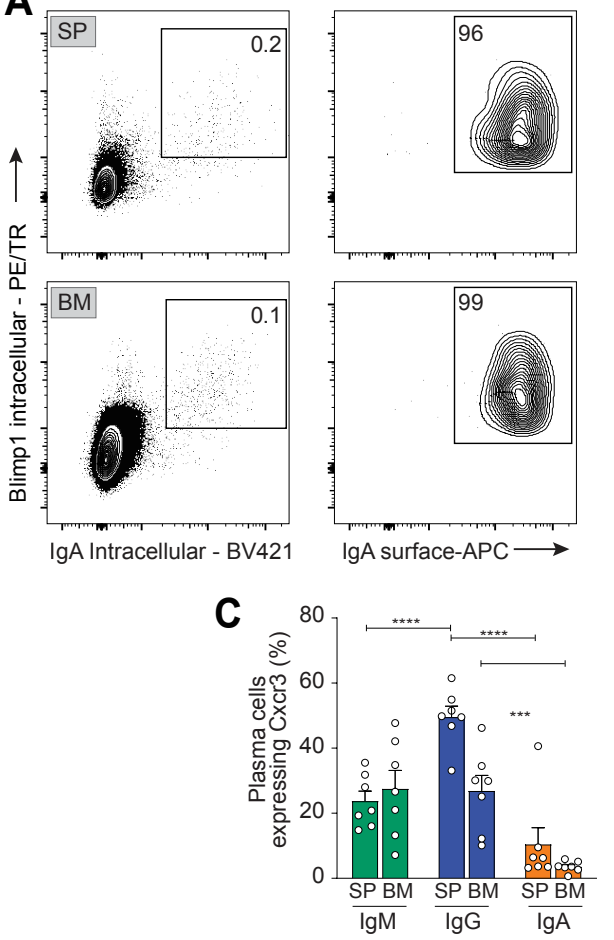
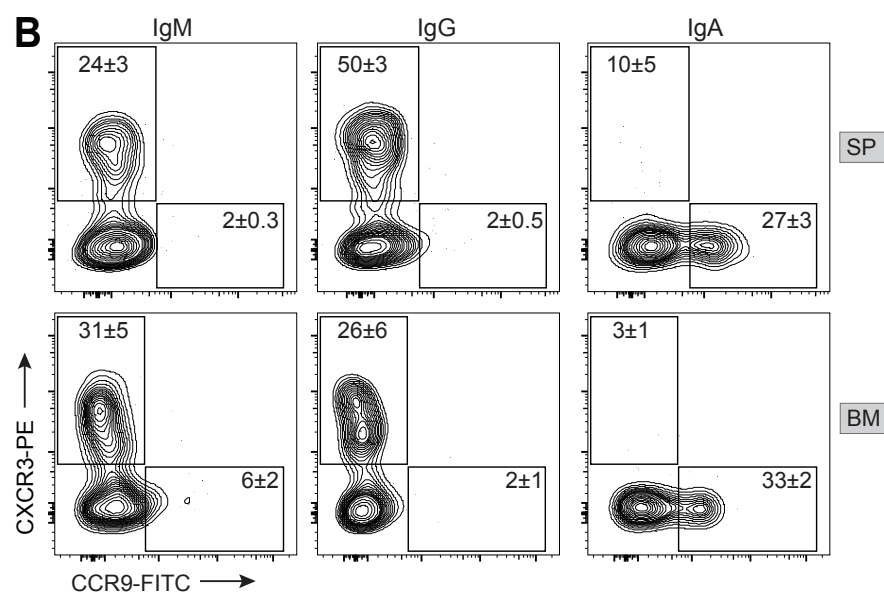

\section{E}
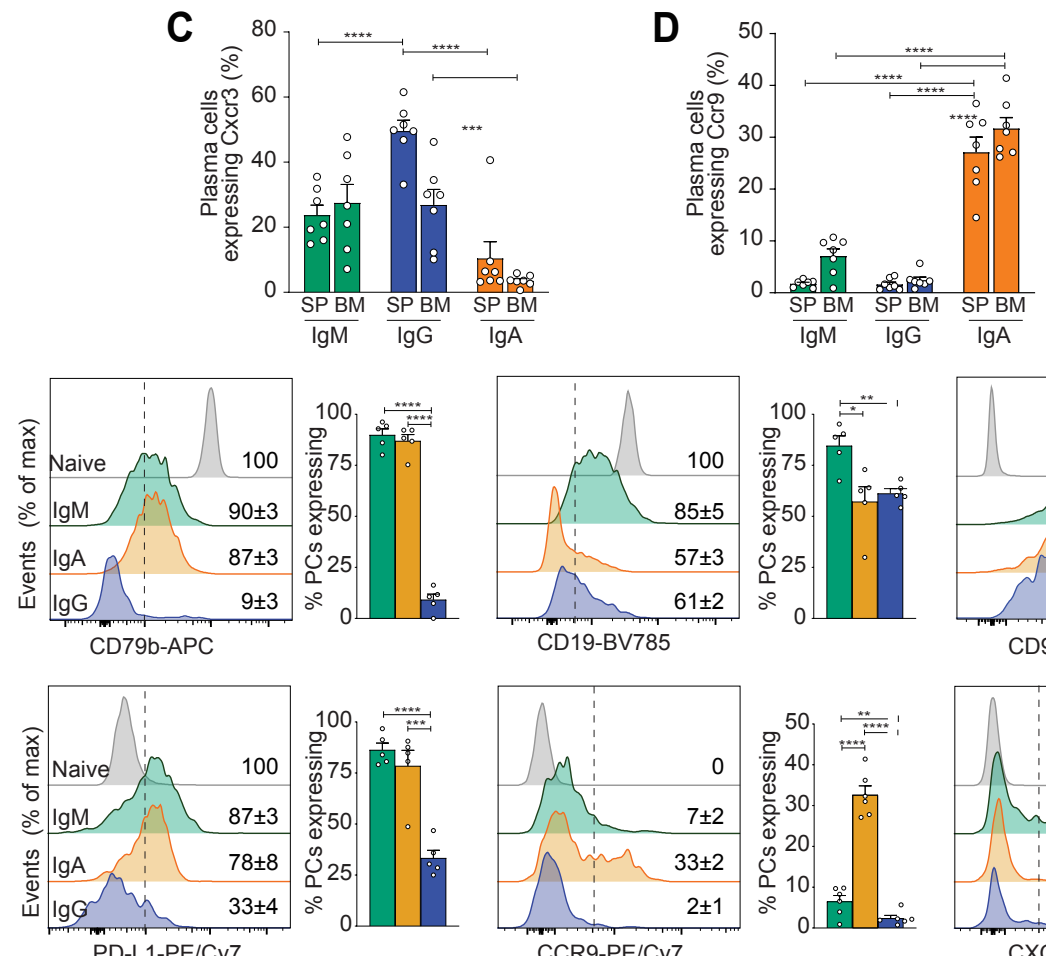

CCR9-PE/Cy7
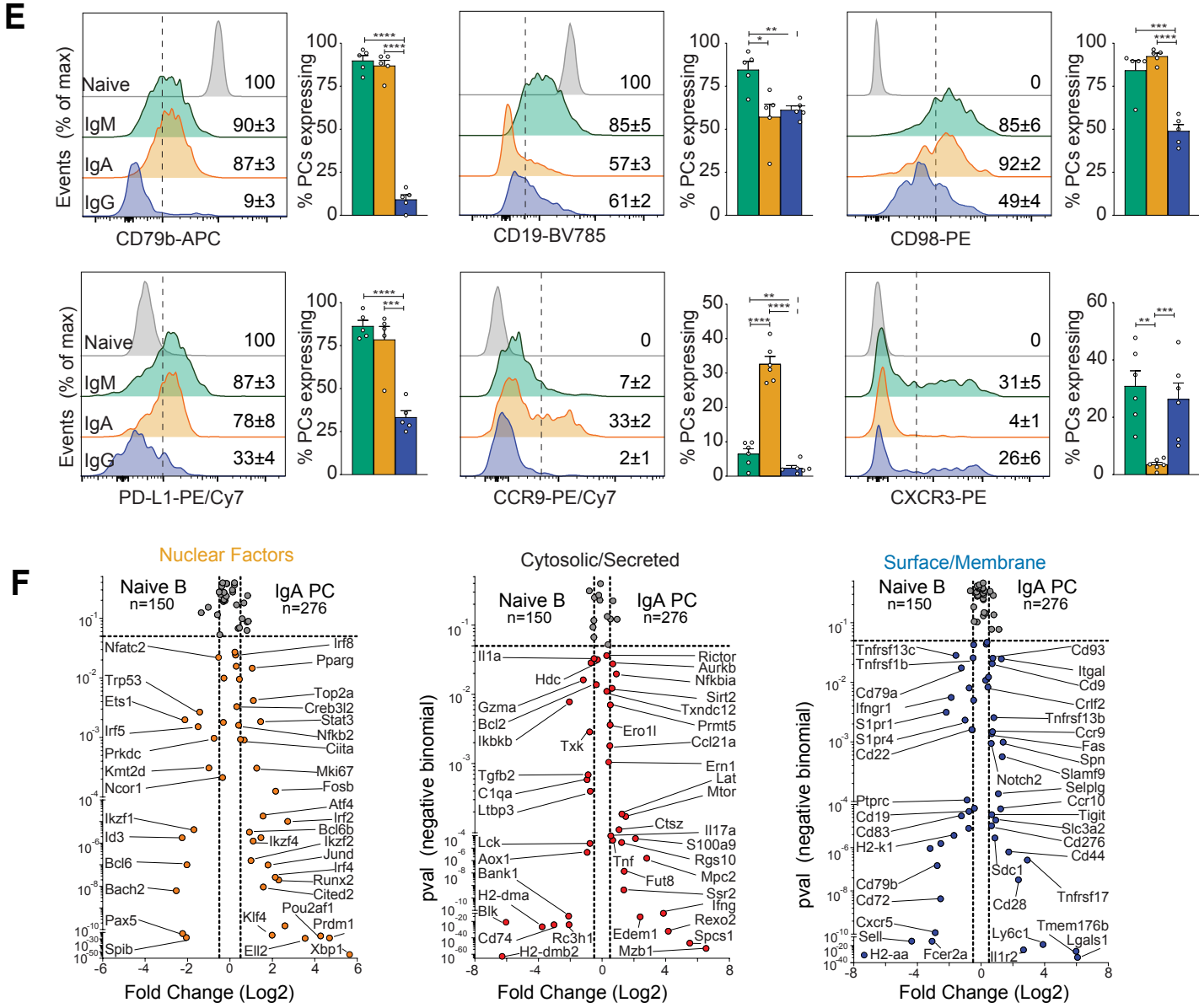

Supplementary Fig 7: Retention of IgA+ PC programming in the bone marrow. (A) Class switched B cells (Gr1-Cd3e-lgM-lgD-, CD19+ and/or CD138+) expressing both intracellular Blimp-1 and intracellular IgA from the SP (top) and BM (bottom) are shown gated for surface IgA. (B) Representative FACs gating of IgM+, IgG+ and IgA+ PCs from the SP (top) and BM (bottom) of unimmunized C57/B6 mice, divided by surface expression of $\mathrm{Cxcr} 3$ and Ccr9. Frequency of PCs of each isotype expressing Cxcr3 is shown in (C) and Ccr9 shown in (D). (For b-d, $n=7$, mean \pm s.em). (E) Expression of surface protein markers from class specific BM PCs compared to naive $B$ cells with percentage of cells expressing listed (mean \pm s.e.m. of $n=6$ ). All statistics 2 -tailed unpaired t test; ${ }^{*} p<0.05,{ }^{* *} p<0.01,{ }^{* * *} p<0.001,{ }^{* * * *}$ $p<0.0001$. ( $F$ ) Differences in gene expression plotted by statistical significance and presented as volcano plots comparing naive $B$ cells (CD19+lgD+lgM+BlimpYFP-CD138-Gr1-CD3e-) and IgA+ PCs sepparated by gene categorization ( $n=150$ naïve B, n=276 lgA PC). 
Supplementary Table 1: Antibodies used in flow cytometry

\begin{tabular}{|c|c|c|c|}
\hline Antibody Target & Clone & Fluorophore & Provider \\
\hline CD79b & HM79-12 & APC & Biolegend \\
\hline NP & - & APC & MMW Lab \\
\hline CD272 (BTLA) & $8 F 4$ & APC & eBioscience \\
\hline $\lg G 1$ & X56 & APC & BD Biosciences \\
\hline $\lg A$ & RMA-1 & APC & Biolegend \\
\hline Streptavidin-APC & - & APC & Biolegend \\
\hline CD38 & 90 & AlexaFluor700 & eBioscience \\
\hline Efluor Viability & - & eFluor 780 & eBioscience \\
\hline $\lg \mathrm{G} 1$ & RMG1-1 & APC-Сy7 & Biolegend \\
\hline CD138 & 281-2 & PE & BD Biosciences \\
\hline CD183 (CXCR3) & 173 & PE & Biolegend \\
\hline CD98 & $4 \mathrm{~F} 2$ & PE & BD Biosciences \\
\hline $\lg G 2 b$ & RMG2b-1 & PE & Biolegend \\
\hline $\lg G 1$ & A85-1 & PE & Biolegend \\
\hline Blimp-1 & 5E7 & PE & BD Biosciences \\
\hline B220 & RA3-6B2 & PE-TR & Biolegend \\
\hline Blimp-1 & 6D3 & PE-TR & BD Biosciences \\
\hline GR1 & RB6-8C5 & PE-Cy5 & Biolegend \\
\hline CD3e & 2C11 & PE-Cy5 & Biolegend \\
\hline $\mathrm{F} 4 / 80$ & BM8 & PE-Cy5 & eBioscience \\
\hline PD-L1 & $10 f .9 g 2$ & PE-Cy7 & Biolegend \\
\hline B220 & RA3-6B2 & PE-Cy7 & Biolegend \\
\hline CXCR3 & CXCR3-173 & PE-Cy7 & Biolegend \\
\hline CCR9 & CW1.2 & PE-Cy7 & Biolegend \\
\hline $\lg G 2 b$ & $\mathrm{R} 12-3$ & FITC & BD Biosciences \\
\hline GL7 & GL7 & FITC & Biolegend \\
\hline Ki67 & $16 \mathrm{~A} 8$ & FITC & Biolegend \\
\hline Fas & J02 & FITC & BD Biosciences \\
\hline CD79b & HM79-12 & FITC & Biolegend \\
\hline $\lg \mathrm{M}$ & 331.12 & PerCP-Cy5.5 & MMW Lab \\
\hline CD138 & $281-2$ & Brilliant Violet 421 & BD Biosciences \\
\hline $\lg A$ & C10-1 & Brilliant Violet 421 & BD Biosciences \\
\hline $\lg \mathrm{G} 1$ & RMG1-1 & Brilliant Violet 421 & Biolegend \\
\hline Streptavidin- BV421 & - & Brilliant Violet 421 & Biolegend \\
\hline I-A/I-E (MHCII) & M5/114.15.2 & Brilliant Violet 510 & Biolegend \\
\hline Streptavadin-BV510 & NA & Brilliant Violet 510 & Biolegend \\
\hline CD19 & 1D3 & Brilliant Violet 510 & BD Biosciences \\
\hline Streptavidin- QD605 & - & Qdot605 & Invitrogen \\
\hline $\lg \mathrm{D}$ & 11.26 & Brilliant Violet 605 & Biolegend \\
\hline CD138 & $281-2$ & Brilliant Violet 605 & Biolegend \\
\hline $\lg \mathrm{M}$ & RMM-1 & Brilliant Violet 605 & Biolegend \\
\hline
\end{tabular}




\begin{tabular}{|cccc|} 
CD19 & $1 \mathrm{D} 3$ & Qdot625 & MMW Lab \\
$\lg D$ & 11.26 & Brilliant Violet 650 & Biolegend \\
$\lg \mathrm{I}$ & $\mathrm{Il} / 41$ & Brilliant Violet 650 & BD Biosciences \\
$\lg \mathrm{C}$ & $\mathrm{C} 10-1$ & Brilliant Violet 711 & BD Biosciences \\
$\mathrm{CD} 19$ & $6 \mathrm{D} 5$ & Brilliant Violet 800 & Biolegend \\
$\lg \mathrm{A}$ & $\mathrm{RMA}-1$ & Biotin & Biolegend \\
Lambda-1 & $\mathrm{R} 11-153$ & Biotin & BD Biosciences \\
IgG2b & RMG2b-1 & Biotin & Biolegend \\
\hline
\end{tabular}

